\title{
Estimating Central Equatorial Pacific SST Variability over the Past Millennium. Part II: Reconstructions and Implications
}

\author{
JULIEN EMILE-GEAY \\ Department of Earth Sciences, University of Southern California, Los Angeles, California \\ KIMBERLy M. COBB \\ Department of Earth and Atmospheric Sciences, Georgia Institute of Technology, Atlanta, Georgia \\ Michael E. MANN \\ Department of Meteorology, The Pennsylvania State University, University Park, Pennsylvania \\ ANDREW T. WITTENBERG \\ NOAA/Geophysical Fluid Dynamics Laboratory, Princeton, New Jersey
}

(Manuscript received 8 September 2011, in final form 3 October 2012)

\begin{abstract}
Reducing the uncertainties surrounding the impacts of anthropogenic climate change requires vetting general circulation models (GCMs) against long records of past natural climate variability. This is particularly challenging in the tropical Pacific Ocean, where short, sparse instrumental data preclude GCM validation on multidecadal to centennial time scales. This two-part paper demonstrates the application of two statistical methodologies to a network of accurately dated tropical climate records to reconstruct sea surface temperature (SST) variability in the Niño-3.4 region over the past millennium. While Part I described the methods and established their validity and limitations, this paper presents several reconstructions of Niño-3.4, analyzes their sensitivity to procedural choices and input data, and compares them to climate forcing time series and previously published tropical Pacific SST reconstructions. The reconstructions herein show remarkably similar behavior at decadal to multidecadal scales, but diverge markedly on centennial scales. The amplitude of centennial variability in each reconstruction scales with the magnitude of the A.D. 1860-1995 trend in the target dataset's Niño-3.4 index, with Extended Reconstructed SST, version 3 (ERSSTv3) > the Second Hadley Centre SST dataset (HadSST2) > Kaplan SST; these discrepancies constitute a major source of uncertainty in reconstructing preinstrumental Niño-3.4 SST. Despite inevitable variance losses, the reconstructed multidecadal variability exceeds that simulated by a state-of-the-art GCM (forced and unforced) over the past millennium, while reconstructed centennial variability is incompatible with constant boundary conditions. Wavelet coherence analysis reveals a robust antiphasing between solar forcing and Niño-3.4 SST on bicentennial time scales, but not on shorter time scales. Implications for GCM representations of the tropical Pacific climate response to radiative forcing are then discussed.
\end{abstract}

\section{Introduction}

One of the largest uncertainties in global climate projections concerns the response of the tropical Pacific Ocean climate system to anthropogenic radiative forcing (Meehl

Corresponding author address: Julien Emile-Geay, Department of Earth Sciences and Center for Applied Mathematical Sciences, University of Southern California, 3651 Trousdale Parkway, Los Angeles, CA 90089-0740.

E-mail: julieneg@usc.edu et al. 2007; DiNezio et al. 2009; Guilyardi et al. 2009; Collins et al. 2010; Vecchi and Wittenberg 2010). In particular, no consensus exists as to the greenhouse response of interannual variability associated with the El Niño-Southern Oscillation (ENSO) or the multidecadal trends in sea surface temperature (SST) over the basin (Yamaguchi and Noda 2006). Such uncertainties arise in part because of difficulties in faithfully simulating tropical climate in coupled general circulation models (CGCMs), and partly because of difficulties in detecting 
anthropogenic-related trends against the rich background of variability characteristic of the tropical Pacific ocean-atmosphere system in relatively short climate records. Indeed, the sparse network of instrumental climate observations from the tropical Pacific rarely extends before A.D. 1900, and very few long, high-resolution paleoclimate records exist from this region.

Recent efforts have focused on resolving the relationship between natural radiative forcing and tropical Pacific climate variability over the last millennium, to determine the tropical Pacific's sensitivity to radiative forcing. This is a critical question that also bears on the future response of the tropical Pacific and ENSO to future climate change, including anthropogenic changes.

Simulations with a widely used intermediate complexity coupled model of tropical Pacific climate (Zebiak and Cane 1987) have suggested a response to natural solar and volcanic forcing in which globally positive radiative forcing anomalies generate cool SST anomalies local to the cold tongue region (Mann et al. 2005; Emile-Geay et al. 2007, 2008). The "ocean dynamical thermostat" hypothesis (Clement et al. 1996) states that since surface warming in the eastern equatorial Pacific is inhibited because of continual upwelling of cooler waters from the deep, this would enhance the westward SST gradient along the equator, boost the trade winds, and further shoal the thermocline in the east, thereby amplifying the vertical advective cooling of the east Pacific SST. If this vertical advective cooling and subsequent amplification by the Bjerknes feedback (Bjerknes 1969) were sufficiently strong, they could overcome the enhanced radiative forcing in the equatorial eastern Pacific, so that the SST might actually cool in that region even as the rest of the tropics warmed. Therefore, given relatively high solar irradiance during the Medieval Climate Anomaly (MCA), and a concentration of relatively large volcanic eruptions in the tropics during the Little Ice Age (LIA), the ocean dynamical thermostat would predict relatively cool conditions during the MCA and warmer conditions during the LIA (Mann et al. 2005).

The intermediate complexity model, however, omits additional processes that might counteract the ocean dynamical thermostat in the event of globally enhanced solar heating or reduced longwave cooling. The first is the warming of midlatitude surface waters, which could eventually penetrate into the equatorial thermocline and upwell at the equator, weakening the ocean dynamical thermostat (Liu 1998). The second is an increased near-surface specific humidity and increased thermal stratification of the tropical troposphere, which would suppress convective overturning (Knutson and Manabe 1995; Held and Soden 2006) and could in turn weaken the trade winds along the equator and overwhelm the ocean dynamical thermostat-as inferred from both observed and simulated trends of sea level pressure over the twentieth century (Vecchi et al. 2006).

It is not yet clear what net impact these opposing feedbacks would have on the eastern equatorial Pacific response to radiative forcing changes. Indeed, the outcome may depend on both the details of the radiative forcing and (in models) the representation of subgridscale processes (e.g., atmospheric convection, clouds, or oceanic vertical mixing), which play critical roles in these feedbacks. For the anthropogenic warming case, the ocean dynamical thermostat and atmospheric lapse rate effects in the east Pacific appear to nearly cancel in most CGCMs (DiNezio et al. 2009; Xie et al. 2010). In addition, most fully coupled ocean-atmospheric GCMs show a weak cold tongue response, if any, to observed solar and volcanic forcing (e.g., Schneider and Zhu 1998; Meehl et al. 2003; Ammann et al. 2007; McGregor and Timmermann 2011). That the net response of the equatorial Pacific depends sensitively on poorly understood subgrid-scale processes and feedbacks (e.g., Capotondi et al. 2006; Kim et al. 2008; Anderson et al. 2009) suggests that long-term reconstructions of this response could potentially provide a very helpful constraint for model simulations.

Several key paleoclimate records generally support cooler central to eastern equatorial Pacific SSTs during the MCA, lending tentative support to the ocean dynamical thermostat hypothesis discussed above. Although they are discontinuous, fossil corals from the central tropical Pacific provide direct evidence for cooler SSTs during the MCA (Cobb et al. 2003), and lower-resolution sediment cores from the tropical Pacific contain prominent anomalies consistent with MCA cooling (Rein et al. 2004; Newton et al. 2006; Khider et al. 2011). Further support for a cooler tropical Pacific comes from evidence for severe drought in ENSO-sensitive locations across the Pacific basin, most notably the southwestern United States (Cook et al. 2004; Herweijer et al. 2007; Graham et al. 2007; Seager et al. 2007). However, recent sedimentary records have documented tropics-wide hydrological changes (Moy et al. 2002; Conroy et al. 2009; Sachs et al. 2009; Tierney et al. 2010), which suggest that previous studies could be reinterpreted as consistent with warmer MCA SSTs in the eastern equatorial Pacific, partially obscured by large meridional excursions of the intertropical convergence zone (ITCZ). Yet another explanation (Graham et al. 2011) is that much of the proxy evidence around the world during the MCA can be explained by forcing an atmospheric GCM with an SST pattern similar to that of Mann et al. (2009, hereafter M09) the key driving anomalies being located in the western Pacific/Indian Ocean SST rather than the central 
and equatorial Pacific. These discrepancies illustrate the difficulties associated with extrapolating large-scale climate patterns from a select handful of individual proxy records, and highlight the need for a unifying mathematical framework in which all the relevant proxy data can be synthesized.

Multiproxy reconstructions of tropical Pacific SST aim to combine the common signals contained in a comprehensive network of proxy records to provide continuous, quantitative reconstructions that can be rigorously compared against radiative forcing histories and climate model output. In Part I of this article (Emile-Geay et al. 2013, hereafter Part I) we described two such methodologies [composite plus scale (CPS) and regularized expectation maximization (RegEM) truncated total least squares (TTLS)] and evaluated their performance on a comprehensive network of high-resolution paleoclimate records from the tropical Pacific and adjacent regions. Frozen network analysis (FNA) suggested that RegEM TTLS enables skillful reconstructions of about $50 \%$ of the total Niño-3.4 variance back to A.D. 1000, but that low-frequency (LF) skill is highly dependent on network density and instrumental target. The CPS was only found to be informative at high frequencies $\left(f>0.1 \mathrm{yr}^{-1}\right)$. Pseudoproxy experiments lent support to the notion that our method and network would reliably estimate the phase of forced LF variability, albeit with inevitable amplitude loss and a bias toward the calibration mean. They also suggest that LF skill is systematically underestimated by FNA analysis with this network and methodology.

We now apply this approach to three instrumental datasets [Extended Reconstructed SST, version 3 (ERSSTv3), the Second Hadley Centre SST dataset (HadSST2), and Kaplan SST] and assess the impacts of various procedural choices, with emphasis on the uncertainties in the reconstruction of LF variability. Although these uncertainties are significant, we find a number of robust features that challenge current GCM paradigms of tropical Pacific variability: multidecadal variability is much more vigorous than predicted by our two GCMs and forcing scenarios, and Niño-3.4 SST appears to have fluctuated roughly out of phase with solar forcing, at least on 200-yr time scales, over the past 800 years. The paper is structured as follows: we start with a brief summary of the methodology (section 2), before presenting a synopsis of the results (section 3), investigating the effect of some procedural choices. In section 4 we present our best estimates of tropical Pacific SST variability over the past millennium, comparing it to published reconstructions of Niño-3.4 and radiative forcing histories. We then discuss their dynamical implications (section 5) before concluding in section 6 .

\section{Methodology}

The reader is referred to Part I for a comprehensive exposition of the reconstruction methodology; only a brief summary is given here. We use a network of accurately dated tropical records from the circum-Pacific region (dating uncertainty of $5 \mathrm{yr}$ or less), covering the past millennium with an increasing degree of sparsity back in time. All reconstructions target the Niño-3.4 index, defined as the average SST anomaly in the region $5^{\circ} \mathrm{N}-5^{\circ} \mathrm{S}, 170^{\circ}-120^{\circ} \mathrm{W}$ (e.g., Trenberth 1997). Because of documented discrepancies between the early instrumental estimates of tropical Pacific SST (Vecchi et al. 2008; Karnauskas et al. 2009; Deser et al. 2010; Yasunaka and Hanawa 2010), we used three datasets derived from the HadSST2 (Rayner et al. 2006), Kaplan SST (Kaplan et al. 1997), and ERSSTv3 (Smith et al. 2008) analyses (Fig. 1). Missing values in HadSST2 were imputed via RegEM with individual ridge regression (Schneider 2001); we refer to the completed dataset as HadSST2i (see Part I). To minimize overfitting, we found it necessary to screen proxy networks against the respective target index prior to applying our reconstruction methods. The network obtained with HadSST2i screening is depicted in Fig. 2 (cf. Fig. 2 of Part I). Using other screening targets results in minor differences (four series at most; Table 1), all after A.D. 1553, so the screening procedure alone does not introduce any difference prior to this time.

To assess the sensitivity to the statistical methodology, we used two different approaches: the simple CPS (Bradley and Jones 1993; Esper et al. 2002; Jones and Mann 2004) and the more sophisticated hybrid RegEM (Schneider 2001; Rutherford et al. 2005) with TTLS regularization (Fierro et al. 1997). It was found in Part I that only RegEM TTLS produces meaningful LF reconstructions, which were validated with both FNA and pseudoproxy experiments (PPEs). The PPE results suggest the following:

- The RegEM TTLS succeeds in estimating about $50 \%$ of the total variance. This skill is partitioned roughly like the spectral density of the target Niño-3.4 index. In the PI simulation (see section 5a of Part I for descriptions of the PI and LM simulations), interannual variability overwhelms LF variability, so only the former component is reliably reconstructed. In the LM forced simulation, LF variability is much stronger, and we find that RegEM TTLS has maximum skill in that frequency band. Instrumental Niño-3.4 estimates of the ratio of LF to high-frequency (HF) variability are most compatible with the LM case, suggesting that our network would reconstruct about $50 \%$ of LF variability back to A.D. 1200.

- The FNA tends to overestimate HF skill and underestimate LF skill, sometimes dramatically so (see 


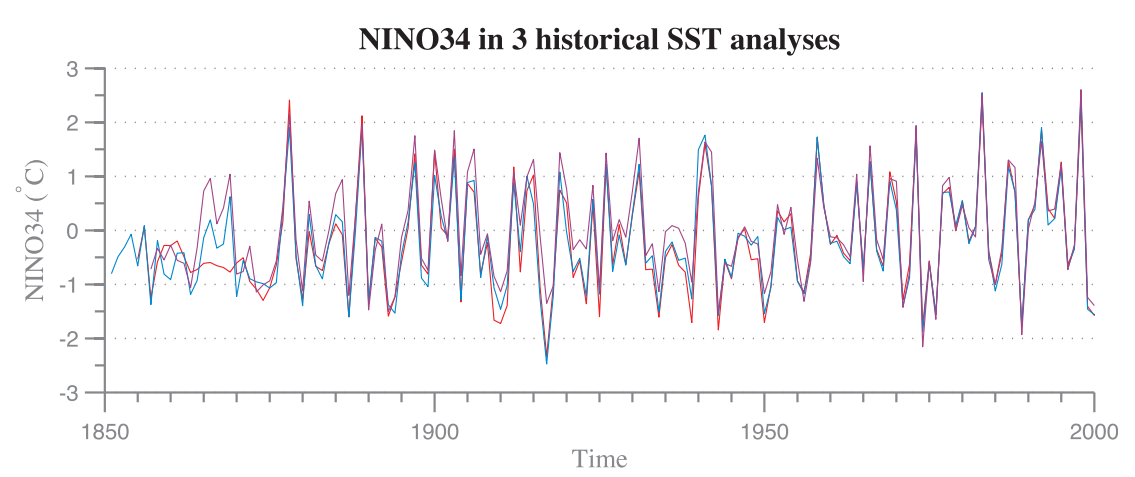

idem, 10-year lowpass filter

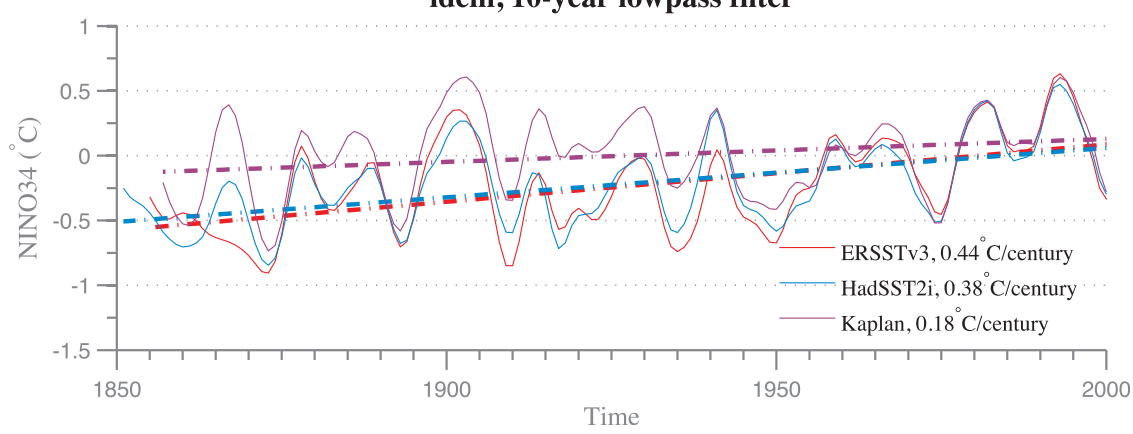

FIG. 1. (top) Niño-3.4 index in three major datasets: HadSST2i [interpolated version of Rayner et al. (2006); blue], Kaplan SST (Kaplan et al. 1997; purple), and ERSSTv3 (Smith et al. 2008; red). Results shown are December-February (DJF) averages of monthly data. (bottom) The 10-yr low-pass-filtered time series; linear trends are shown in dashed lines of the respective color, with magnitudes in the figure legend. See Part I for details.

Figs. 11 and 12 of Part I). Our FNA calibration/ verification exercises reveal a systematic bias that results from the necessary use of relatively short calibration $(\sim 100 \mathrm{yr})$ and verification $(45 \mathrm{yr})$ intervals, whereas the actual reconstructions utilize the full instrumental record for calibration (as do PPEs). This underscores the importance of providing various assessments of the reliability of a reconstruction.

Millennium-long RegEM reconstructions were constructed by splicing together shorter segments made with proxies from each 100 -yr-long nest. Specifically, an A.D. 1000-1995 reconstruction was undertaken using only proxies available in the nest A.D. 1000-99. Then, an A.D. 1100-1995 reconstruction was undertaken using only proxies available in the nest A.D. 1100-99. This process was repeated forward in time, with the final splice incorporating RegEM solutions from the most recent network (A.D. 1800-50 for HadSST2i, A.D. 1800-53 for ERSSTv3, and A.D. 1800-56 for Kaplan). Although some studies have used FNA as a way of guiding the splicing of such segments so that only networks that improve reconstruction skill are added (Mann et al. 2008; M09), we found this approach ineffective here, for the reasons mentioned above. Segments were therefore spliced in chronological order. We stress that our FNA and PPE results are specific to this study and cannot a priori be generalized to previously published work.

\section{A synoptic view of tropical Pacific reconstructions}

We now present our reconstructed Niño-3.4 time series based on the proxy network and methods just described. Because HadSST2i depicts a middle-ofthe-road scenario for the evolution of Niño-3.4 over the instrumental era (Fig. 1), we start with reconstructions targeting this index before evaluating the influence of the target SST dataset and other procedural choices.

\section{a. Niño-3.4 reconstructions and their uncertainties}

\section{1) UNCERTAINTY QUANTIFICATION}

The output of both reconstruction methods must be viewed in the context of their uncertainties. As noted by Jones et al. (2009), residuals between reconstructions and observations computed over a subset of the instrumental period may underestimate the total error. We assess the latter via two complementary measures: 


\section{HadSST2i target (36 records)}

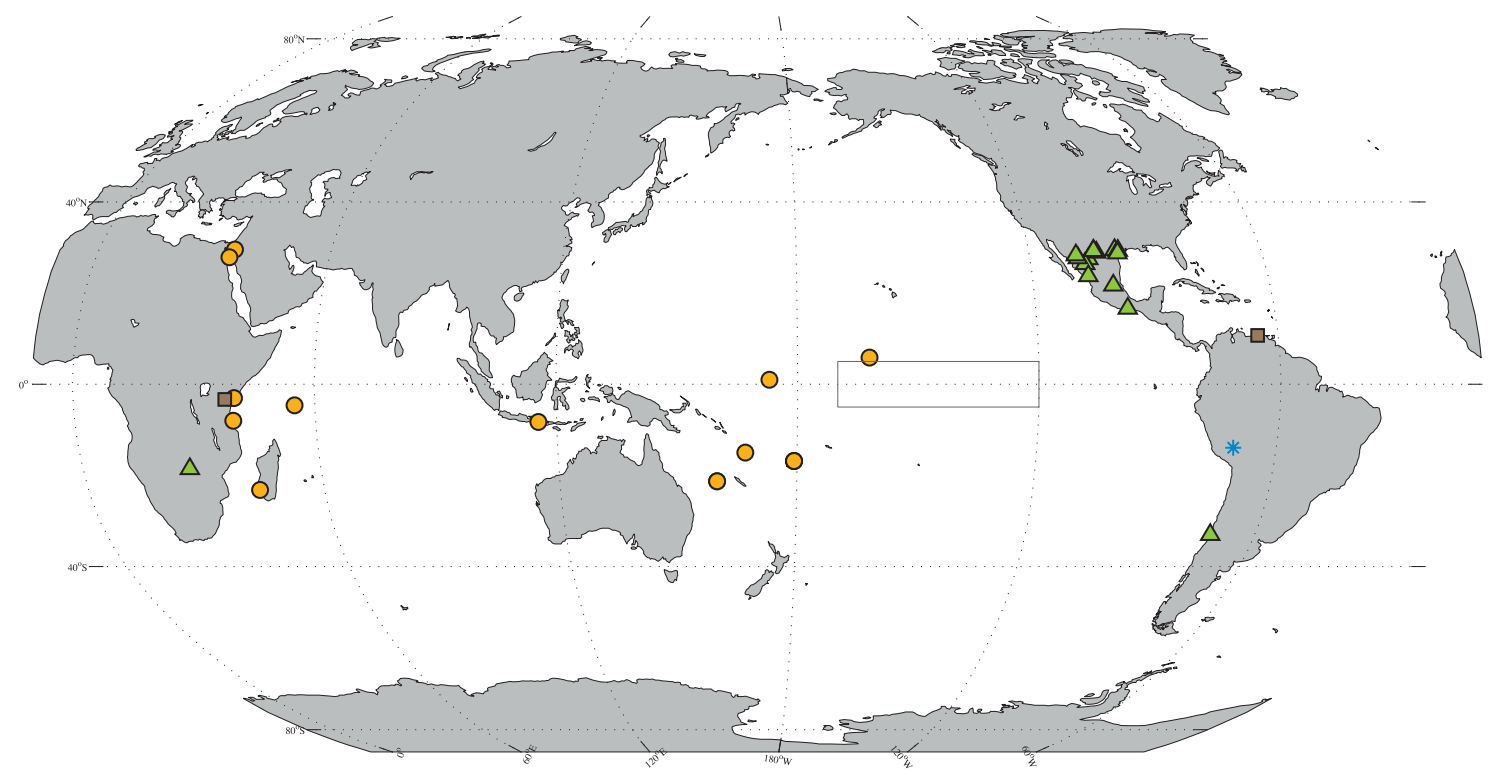

Proxy availability

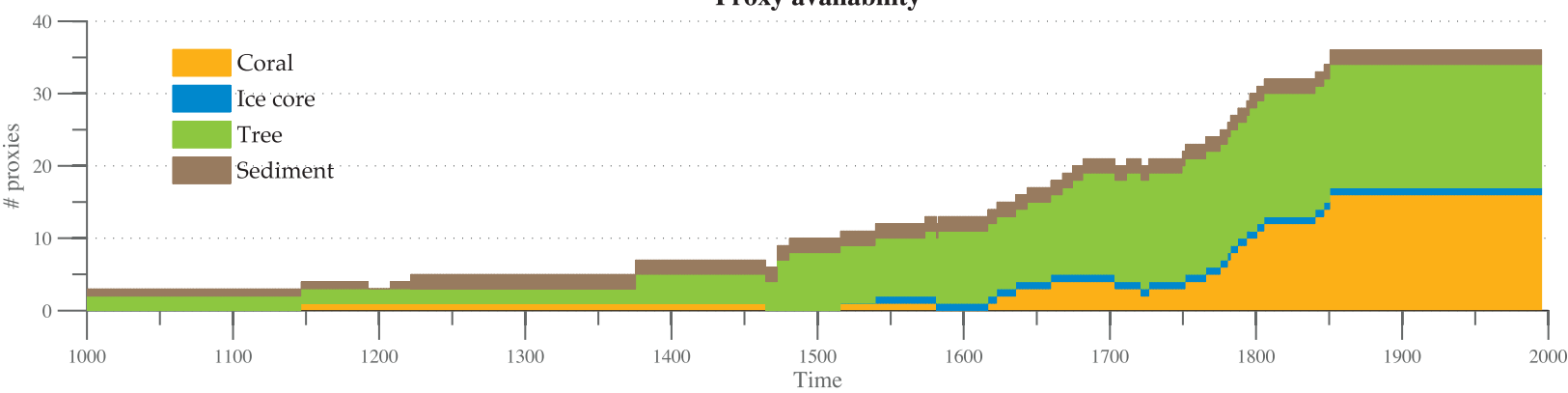

FIG. 2. Proxy database: spatiotemporal characteristics after screening for significant relationships with the HadSST2i Niño-3.4 target. (top) Location of proxy archives. The Niño-3.4 region is indicated by the black box. (bottom) Temporal distribution of proxies.

- A jackknife estimate of sampling variability (Efron 1981), which assesses the sensitivity of the reconstruction to the inclusion of a given proxy series (CPS and RegEM). The jackknife consists in of withholding one proxy predictor at a time from the analysis; it was preferred over other resampling plans such as the bootstrap because it guarantees a nonempty set of predictors in each nest, unlike the bootstrap. The spread between jackknife reconstructions is a measure of the sensitivity of the full reconstruction to the removal of one predictor; narrow intervals mean robust reconstructions, whereas wide ones reflect the large influence of one or more proxy series.

- An estimate of imputation error (Schneider 2001), which provides a heuristic measure of the reliability of the reconstruction based on the magnitude of regression residuals (RegEM only). The generalized cross validation (GCV) estimate of standard error (Wahba 1990) used in RegEM is

$$
\sigma_{R}=\frac{n-1}{n-1-p_{\text {eff }}} \sigma_{N},
$$

where $\sigma_{N}$ is the estimated standard deviation of Niño-3.4 residuals, $n$ is the number of points in the calibration interval (145 for HadSST2i), and $p_{\text {eff }}$ is the effective number of parameters of the model (here the TTLS truncation level). Because RegEM imputes missing values near the center of their (Gaussian) distribution, it is known to underestimate variance when few predictors are present (Schneider 2006). Based on numerical experiments, 
TABLE 1. Compositional differences introduced by the screening process. Note that two screened networks differ by at most four records. Shown are the Amedée Lighthouse record from Quinn et al. (1998), Ras Umm Sid record from Felis et al. (2000), Zimbabwe precipitation record from Therrell et al. (2006), and Nevado de Colima record from ITRDB (2009).

\begin{tabular}{lcccc}
\hline \hline & \multicolumn{4}{c}{ Proxy record } \\
\cline { 2 - 5 } SST target & $\begin{array}{c}\text { Amedée } \\
\text { Lighthouse }\end{array}$ & $\begin{array}{c}\text { Ras Umm } \\
\text { Sid }\end{array}$ & Zimbabwe & $\begin{array}{c}\text { Nevado } \\
\text { de Colima }\end{array}$ \\
\hline ERSSTv3 & No & No & No & Yes \\
HadSST2i & No & Yes & Yes & No \\
Kaplan SST & Yes & Yes & Yes & No \\
\hline
\end{tabular}

we correct for this effect by inflating error estimates by a conservative factor of 1.3 . Given the Gaussian context, approximate $95 \%$ confidence intervals can be obtained via the familiar $\left(X-1.96 \sigma_{R}\right.$, $\left.X+1.96 \sigma_{R}\right)$.

It is important to stress, however, that these two error estimates measure different things and are therefore not expected to coincide.

\section{2) CPS RESUltS}

The CPS results are displayed in Fig. 3. The top panel shows how well the reconstructed Niño-3.4 series reproduces the instrumental Niño-3.4 for both the raw and low-pass-filtered Niño-3.4, as quantified by reduction of error (RE) scores. Calibration scores suggest that $54 \%$ of the total variance, and none of the LF variance, is successfully recovered. However, it was shown in Part I that verification scores rarely breach the significance benchmarks before A.D. 1850. We also found CPS to be an ineffective method to reconstruct centennial variability with our network, although it provides a valuable assessment of decadal and shorterscale variability. Reconstructions back to A.D. 1000 are shown on the lower panel, displaying vigorous decadal variability (comparable or greater to that observed over the instrumental era) centered around a flat baseline, an expected consequence of the variance matching technique employed by CPS. The jackknife envelopes widen markedly before A.D. 1200 because of the very low number of proxy predictors then. Interannual variance appears to decrease back in time, except for a century-long interval centered around A.D. 1480; if true, this would support the notion that twentieth-century ENSO variance is exceptional in the context of the past five centuries and beyond (Gergis and Fowler 2006). Yet we find this pattern to be driven by two distinct factors:
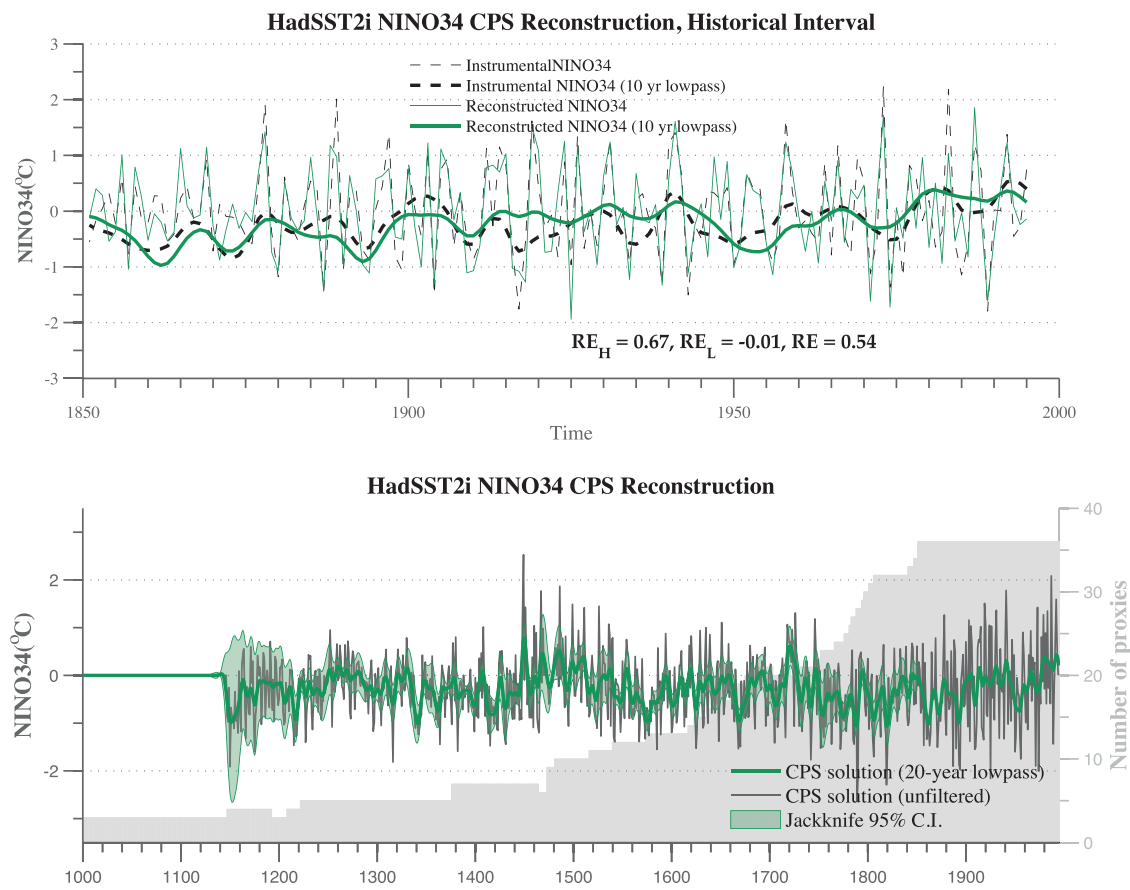

FIG. 3. The CPS solution for the HadSST2i Niño-3.4 target. (top) The A.D. 1857-1995 historical interval and the raw and LF validation statistics (denoted by the subscript $L$ ). (bottom) The unfiltered (black) and 20-yr low-pass-filtered (green) reconstructed Niño-3.4 index over the entire millennium, together with jackknife confidence intervals for the latter. The gray shaded region depicts the availability of proxies through time. The reconstruction was set to zero prior to A.D. 1146, when only three series are available and skill is very low (see Part I for details). 
- A calibration RE score of 0.67 means that only twothirds of the variability is faithfully captured over the most well-observed interval, with further reductions driven by decreasing proxy availability back in time.

- Dating errors as small as 1-2 yr may produce destructive interferences on interannual time scales, even for signals that show good coherency over the instrumental record. Indeed, two 4-yr periodic harmonic signals cancel each other with a 2-yr phase lag, so we may expect commensurate dating errors to lower correlations between highresolution records, as illustrated between tree-ring chronologies and coral records by Li et al. (2011).

\section{3) REGEM RESULTS}

We plot in Fig. 4 the RegEM solution using the same input data (HadSST2i target). Vigorous decadal variability is also a notable feature of this estimate, superimposed onto pronounced centennial excursions. The reconstruction reveals generally cool conditions broadly coincident with the LIA (A.D. 1600-1800), a relatively warm interval around the fifteenth century (when Niño3.4 approaches late-twentieth-century levels) and relatively cool conditions during part of the MCA (A.D. 1150-1300). Large excursions at both HF and LF prior to A.D. 1146 are likely a consequence of the low number of high-quality proxy predictors, as both FNA and PPE results (Part I) showed very little skill with this extremely reduced network of three proxies-these fluctuations should therefore be interpreted with extreme caution. Interannual variability tends to be lower prior to the calibration interval, an expected consequence of regression dilution (Frost and Thompson 2000), confirmed by HF RE scores between 0.4 and 0.6 for all networks (Fig. 4 of Part I). Note, however, that these scores might somewhat overestimate HF skill and underestimate LF skill (Part I). The centennial modulations in interannual variance are of a less systematic nature than in the CPS reconstructions, but are especially pronounced from $\sim$ A.D. 1150 to $\sim$ A.D. 1300. A visual inspection of the four proxy records going back before A.D. 1300 reveals no intrinsic reduction in interannual variance in each of them. Instead, the reconstructed decrease is very likely a consequence of a lack of coherency between proxies resulting from dating errors, as explained above. Our pseudoproxy experiments (Part I), however, suggest that reconstructions would faithfully capture the phase of LF fluctuations-immune to dating errors $<5 \mathrm{yr}-$ although their amplitude is likely to be damped.

Both jackknife envelopes and RegEM confidence intervals accompany the LF reconstruction, and show contrasting features: jackknife envelopes are widest before A.D. 1350 and during the LIA, and they are most narrow from approximately A.D. 1400 to A.D. 1600, when RegEM intervals are at their widest. Both are relatively large during the LIA, indicative of divergent estimates of variability given by the relatively large number of proxies available around that period. Discrepancies between uncertainty estimates call for complementary qualitative assessments (see below).

Which proxy or proxies contribute most to our reconstruction? As all regression methods, RegEM is linear in the predictor variables, despite the nonlinear process whereby it computes regression coefficients. Such coefficients provide a direct measure of each proxy's weight in the final reconstruction, and are plotted in Fig. 5 at the midpoint of every nest. Four features are of note: first, the weights are unequal between proxies, reflecting the varying quality of the proxies assessed over the calibration period; this is in contrast to CPS, which assigns equal weights to all predictors, regardless of their quality. Second, certain proxies are irregularly weighted through time [e.g., the North American Drought Atlas (NADA) first principal component (PC1) series of Cook (2008) waxes and wanes in importance]; this reflects the adaptiveness of the method, which looks for signals that are coherent with the covariance structure estimated over the calibration interval. Third, no single proxy series markedly outweighs the others at any point in time, a point also corroborated by the fact that jackknife solutions do not show an outstanding sensitivity to the inclusion of any predictors after A.D. 1100. This is important, as it means that the reconstruction does not depend solely on one proxy, but takes advantage of the information contained in multiple proxies (Mann 2002; Li et al. 2010) to extract a climate signal. It is clear from the A.D. 1050 plot (bottom right) that the estimate is then largely driven by the Lake Challa (Wolff et al. 2011) and Chilean cordillera series (Le Quesne et al. 2006), explaining the strong sensitivity observed over A.D. 1000-1100 with the jackknife analysis. Finally, the coefficients tend to grow back in time, indicating increasing reliance on an ever smaller number of proxies.

While informative, these diagnostics do not quantify the actual contributions of each proxy series to the final reconstruction. To see this, we plot the product of the LF regression weights times the standardized proxy signals in Fig. 6. Several decade-long warming or cooling episodes centered in A.D. 1330, A.D. 1760, and A.D. 1820 show a large degree of coherency between proxy predictors. Two of these epochs are associated with a major drought episodes in North America (Cook et al. 2004): the A.D. 1140-62 megadrought is associated with the demise of the Anasazi civilization (e.g., Dean and Doyel 2006; Weiss and Bradley 2001) and the A.D. 1818-24 drought was one of the strongest to have struck North 


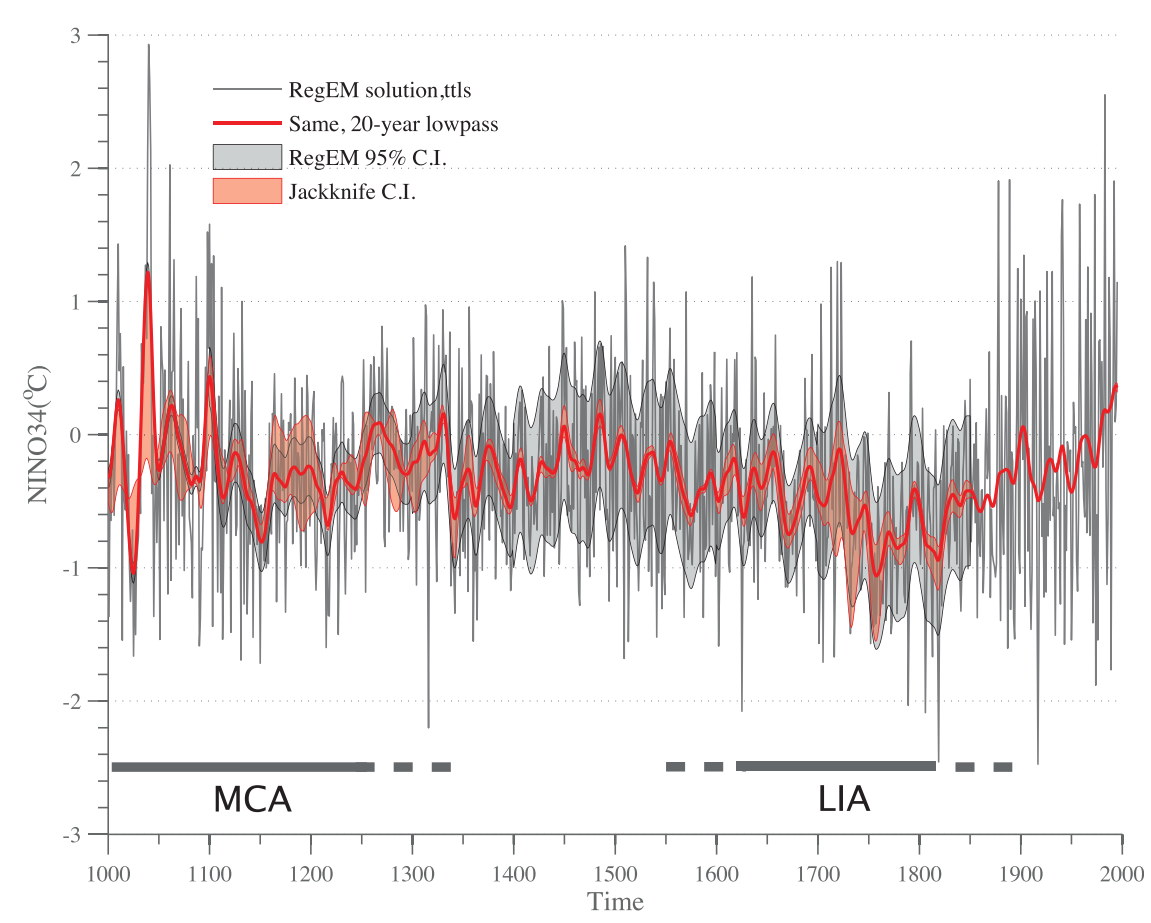

FIG. 4. RegEM solution (TTLS) targeting the HadSST2i Niño-3.4 index. The red shaded region represents the spread of jackknife reconstructions, while the gray shaded region represents RegEM-based confidence intervals.

America in the past 200 years (Fye et al. 2003). The cooling centered around A.D. 1760 coincides with the A.D. 1756-68 "Strange Parallels" drought, which had wide-ranging impacts throughout the tropics (Leiberman 2003; Cook et al. 2010). Since some of the same droughtsensitive tree-ring proxies used to identify North American droughts contribute to our reconstruction (a drought being indicative of cool Niño-3.4 SSTs), it is not surprising to see dendrochronological records contribute to this cooling. What is especially notable is that these signals are corroborated by multiple independent indicators (corals, sediment cores, and ice cores). In contrast, the neutral episode circa A.D. 1450 is marked by opposing signals, with tree-ring proxies suggesting a moderate warming while others suggest no change to a slight cooling (same in A.D. 1485; not shown). Such qualitative measures of consistency between proxy archives provide a complementary assessment of the reconstruction's reliability, and may be used to assess the level of cross-site replication supporting a given anomaly. Note that a similar plot may be drawn at each point in time, but we focus here on four epochs of relative warming or cooling for illustrative purposes.

\section{b. Sensitivity analyses}

We will now evaluate the robustness of these results to key procedural choices: reconstruction method, instrumental target, and coral detrending.

\section{1) SENSITIVITY TO THE RECONSTRUCTION METHOD}

Figure 7 shows the evolution of Niño-3.4 solutions obtained from the three instrumental targets and two reconstruction methods (CPS and RegEM TTLS), together with RegEM-based confidence intervals for the LF component. A salient feature of our reconstructions is that, in each case, the CPS and RegEM solutions display similar LF behavior (they are within uncertainties of each other most of the time), but the CPS reconstruction displays more pronounced decadal variability, while RegEM reconstructions display more pronounced centennial variability: the LIA cooling is virtually absent of CPS reconstructions, for instance. The similarity between the LF character of the CPS and RegEM reconstructions using HadSST2i and Kaplan targets is otherwise remarkable and suggests that the statistical method is of secondary importance here.

\section{2) Sensitivity to the instrumental target}

Figure 8 takes a closer look at the influence of the target dataset and the uncertainties associated with each reconstruction. A consistent feature is the large jackknife uncertainties at A.D. 1350 or so, when only four records are available. Jackknife envelopes are most narrow from $\sim$ A.D. 1400 to A.D. 1500 , surrounding a time of relative 


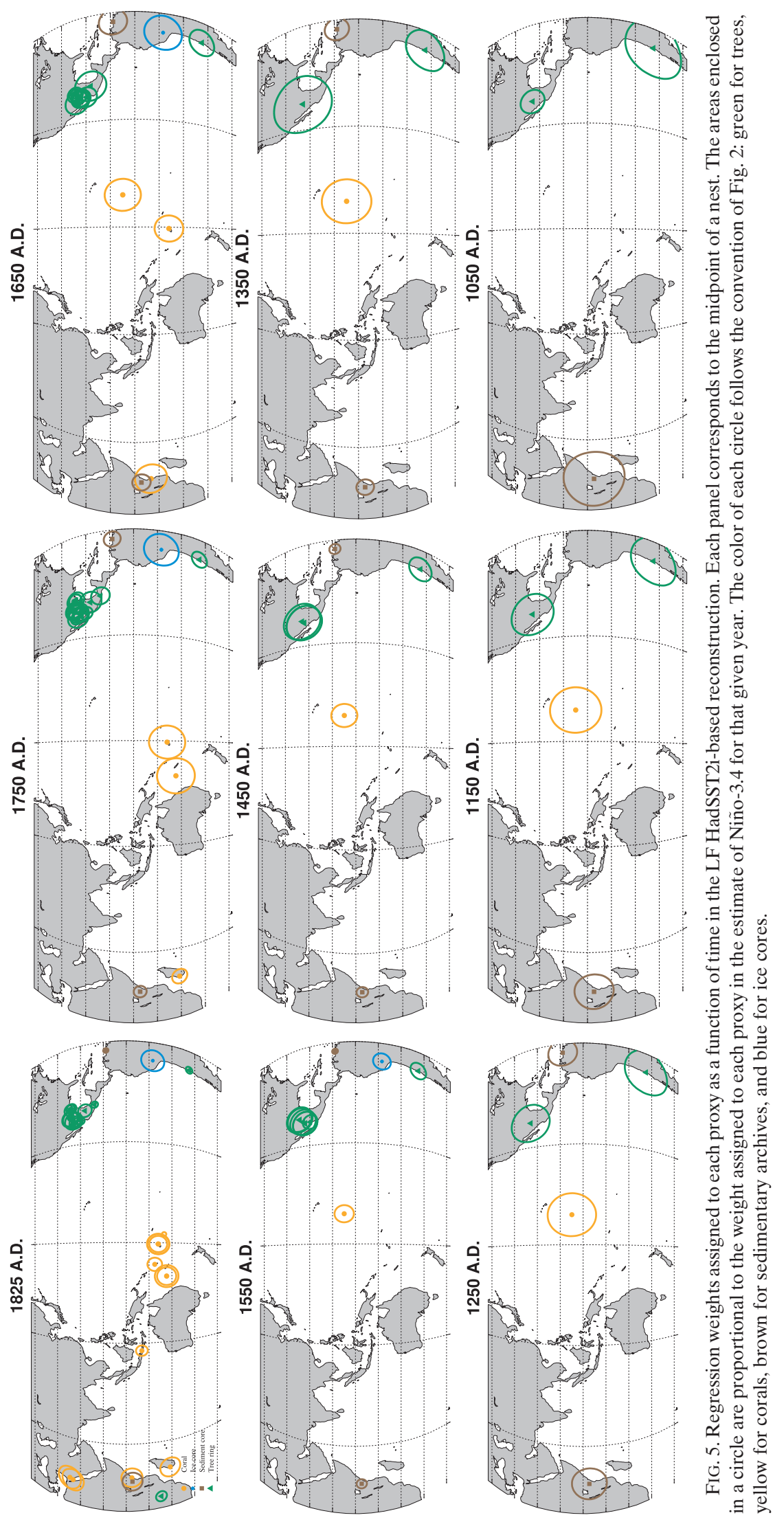



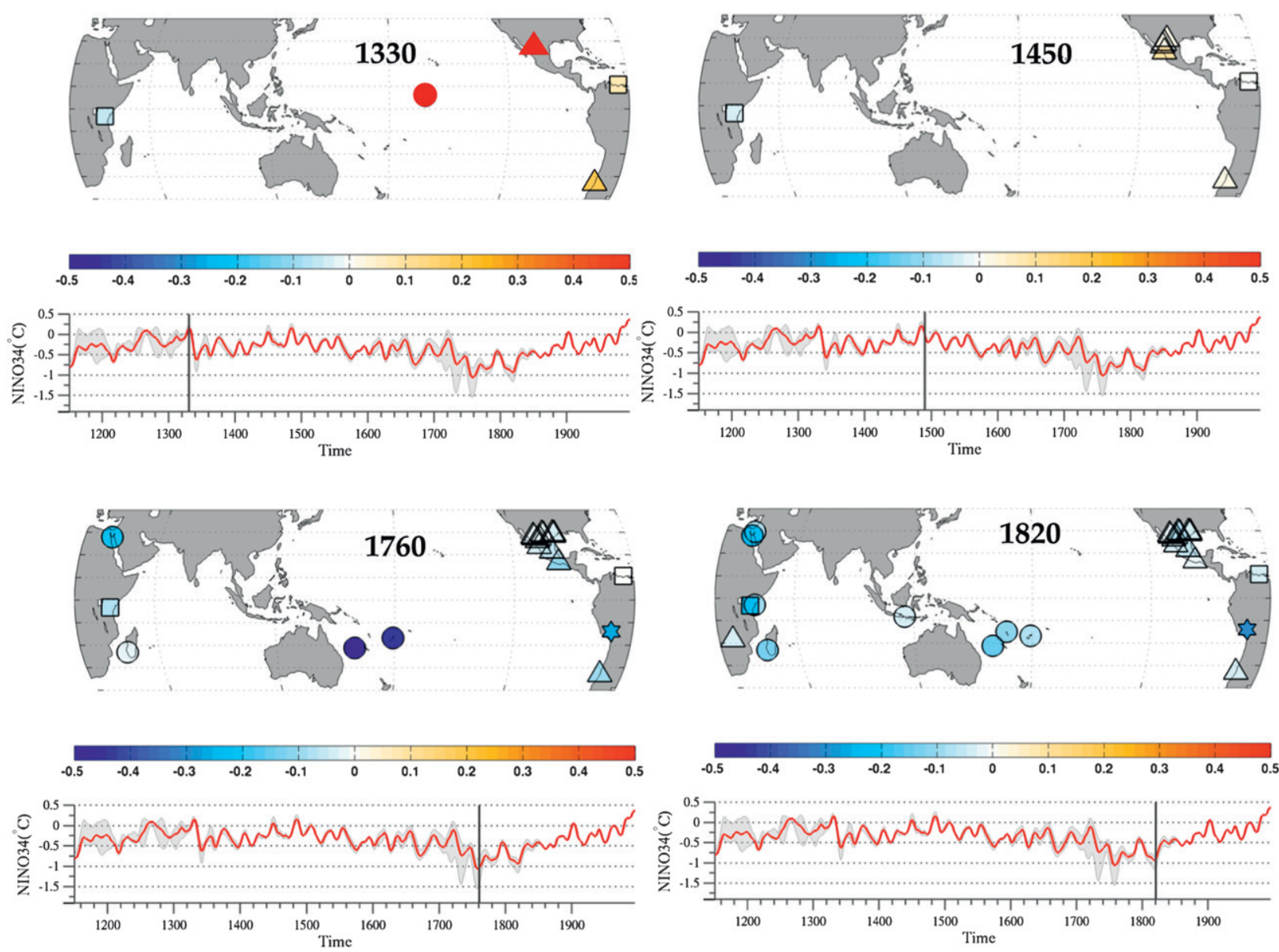

FIG. 6. Proxy contributions to the LF HadSST2-based Niño-3.4 reconstruction. The shape of each symbol follows the convention of Fig. 2: triangles for trees, circles for corals, squares for sedimentary archives, and stars for ice cores. The color of each symbol is the product of the LF regression weights times the proxy signal, coded according to the color scale (from $-0.5^{\circ}$ to $0.5^{\circ} \mathrm{C}$ ) below the map. Time series plots display the 20-yr low-pass-filtered Niño-3.4 and associated jackknife spread. Gray vertical lines mark the timing of each remarkable point.

warmth in all three reconstructions. The reconstruction based on an ERSSTv3 target, however, shows a very wide jackknife spread around A.D. 1550, traceable to the Nevado de Colima [International Tree-Ring Data Bank (ITRDB)] record, which is not present in the other two screened networks. The depth of the minimum about A.D. 1760 noted above appears to scale like the instrumental trend (ERSSTv3 > HadSST2i > Kaplan). This feature dominates other methodological choices.

The spectral densities of our three families of Niño-3.4 reconstructions are depicted in Fig. 9, compared against the Niño-3.4 spectra obtained from the PI (unforced) and LM (forced) simulations. Two LF features are noteworthy. First, reconstructions display noticeably stronger multidecadal (20-30) variability than portrayed by the two GCM simulations, which is remarkable given that reconstructed variability is, by nature, biased low. Second, for the ERSSTv3- and HadSST2i-based reconstructions, there is a broadband spectral peak at the 250 -yr periodicity, which is most compatible with the forced (LM) simulation. As noted before, the amplitude of centennialscale variability appears to be an increasing function of the instrumental trend (ERSSTv3 > HadSST2i > Kaplan). While it is possible that such variability is endogenous in nature, the PI simulation generates a much weaker centennial power than observed here. This suggests that observed Niño-3.4 variability is most compatible with a forced scenario.

\section{3) Sensitivity to Coral Detrending}

Finally, we analyze the sensitivity to the processing of coral time series. Some studies (Wilson et al. 2010, hereafter W10; Ault et al. 2009) take the viewpoint that centennial trends in corals $\delta^{18} \mathrm{O}$ series are too poorly understood to be used for multiproxy temperature reconstruction, and make the choice of detrending such 


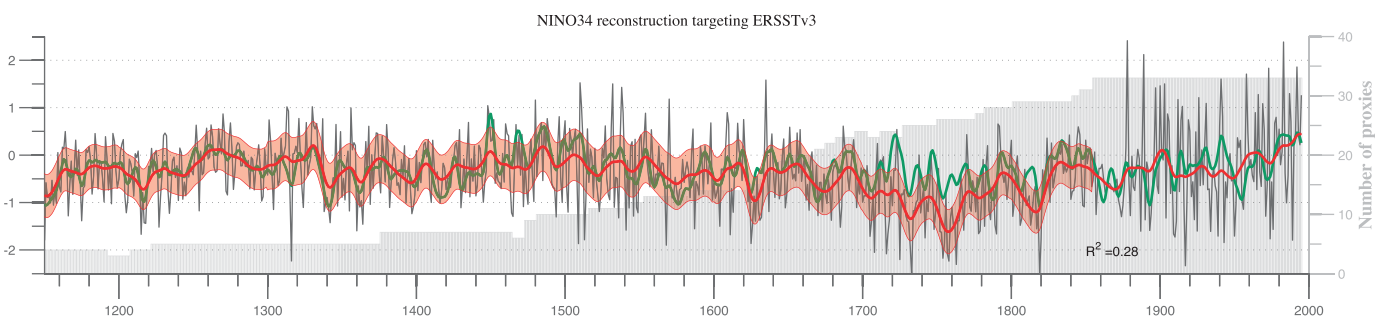

NINO34 reconstruction targeting HadSST2i

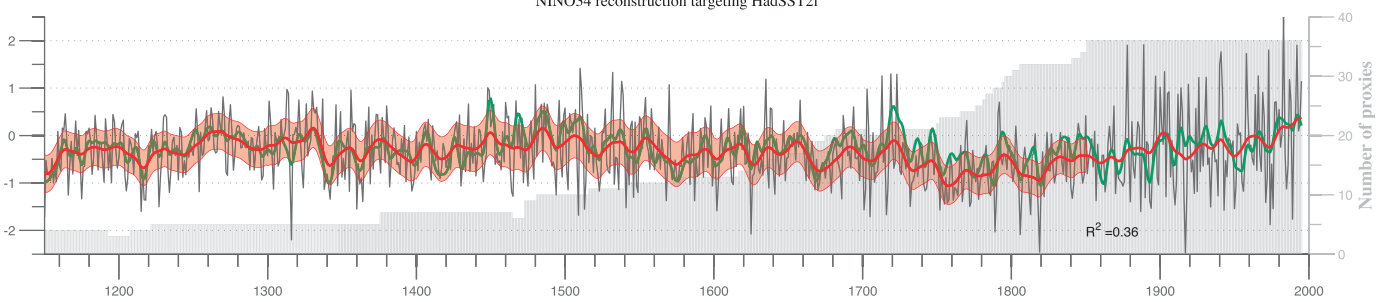

NINO34 reconstruction targeting Kaplan

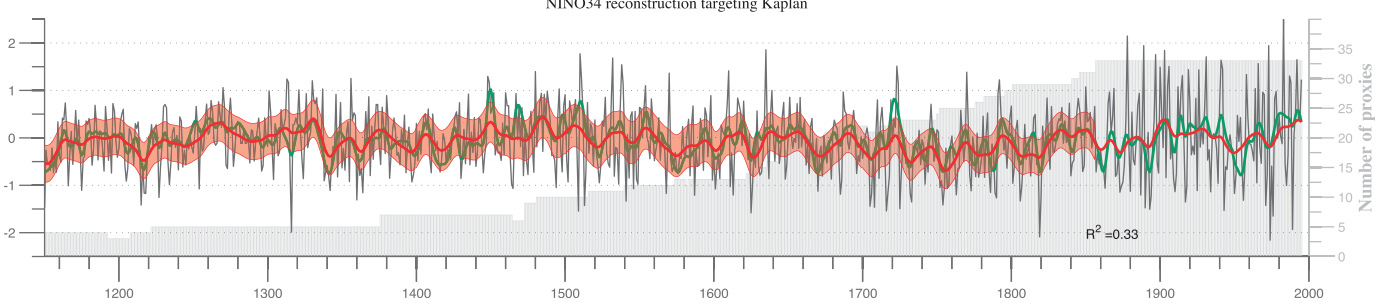

FIG. 7. Most likely trajectories of Niño-3.4 over the past millennium. Plotted for each panel are the 20-yr low-passfiltered RegEM data with 95\% confidence interval (red) and CPS solutions (green), the unfiltered RegEM solution (dark gray), and the number of available proxies (light gray shaded region). Numbers in the lower right corner of each plot are the linear correlation coefficients between 20-yr low-pass-filtered CPS and RegEM solutions. Reconstructions are only plotted after A.D. 1150, before that CPS reconstructions are not defined.

records with a 150-yr spline. This view is partially supported by the analysis of Thompson et al. (2011), who found that up to $40 \%$ of coral $\delta^{18} \mathrm{O}$ trends can be explained by factors other than temperature during the instrumental period. To test the impact of the coral $\delta^{18} \mathrm{O}$ trends, we conducted a series of experiments using similarly detrended coral $\delta^{18} \mathrm{O}$ series (Fig. 10). Coral detrending strongly affects the estimate of LIA cooling episodes, in some cases (HadSST2i) turning the decade surrounding A.D. 1760 into one of the warmest of the millennium. However, LF verification scores are then uniformly negative, casting doubt on the validity of this choice. The effect is weaker before approximately A.D. 1600 (when most coral series have dropped out of the network), but does have the effect of raising Niño3.4 SST by $0.1^{\circ}-0.3^{\circ} \mathrm{C}$ during the A.D. $1150-1450$ period (when Palmyra data are available). By stripping the twentieth-century Palmyra coral of its LF content, similar signals in the fossil Palmyra corals are also removed from the reconstruction. This scenario is likely to be an extreme one, as studies that attempt to deconvolve the temperature versus hydrological contributions to coral $\delta^{18} \mathrm{O}$ trends through a multiproxy approach find that there is a significant temperature contribution to coral $\delta^{18} \mathrm{O}$ trends [e.g., Nurhati et al. (2011) at Palmyra and Hendy et al. (2002) for the Great Barrier Reef].

We conclude that for a given proxy network, the detrending choice and target dataset wield the largest influence on the reconstructed centennial variability. A case can be made that coral detrending jettisons key LF information and should therefore not be done in attempts to reconstruct LF variability. It is, however, disconcerting that the SST target used for calibration should exert such a major control on the LF character of the reconstruction. Complementary tests show this to be the case whether proxy screening is applied or not: it is mostly driven by the weight assigned to each proxy over the calibration interval during the estimate of regression coefficients. Because it is impossible to decide based on current evidence which SST dataset is closer to the truth, and therefore which reconstruction to trust, we now average the three RegEM solutions together to obtain a millennial history of Niño-3.4 SST. We shall discuss the significance of this instrumental divergence in section 5 . 

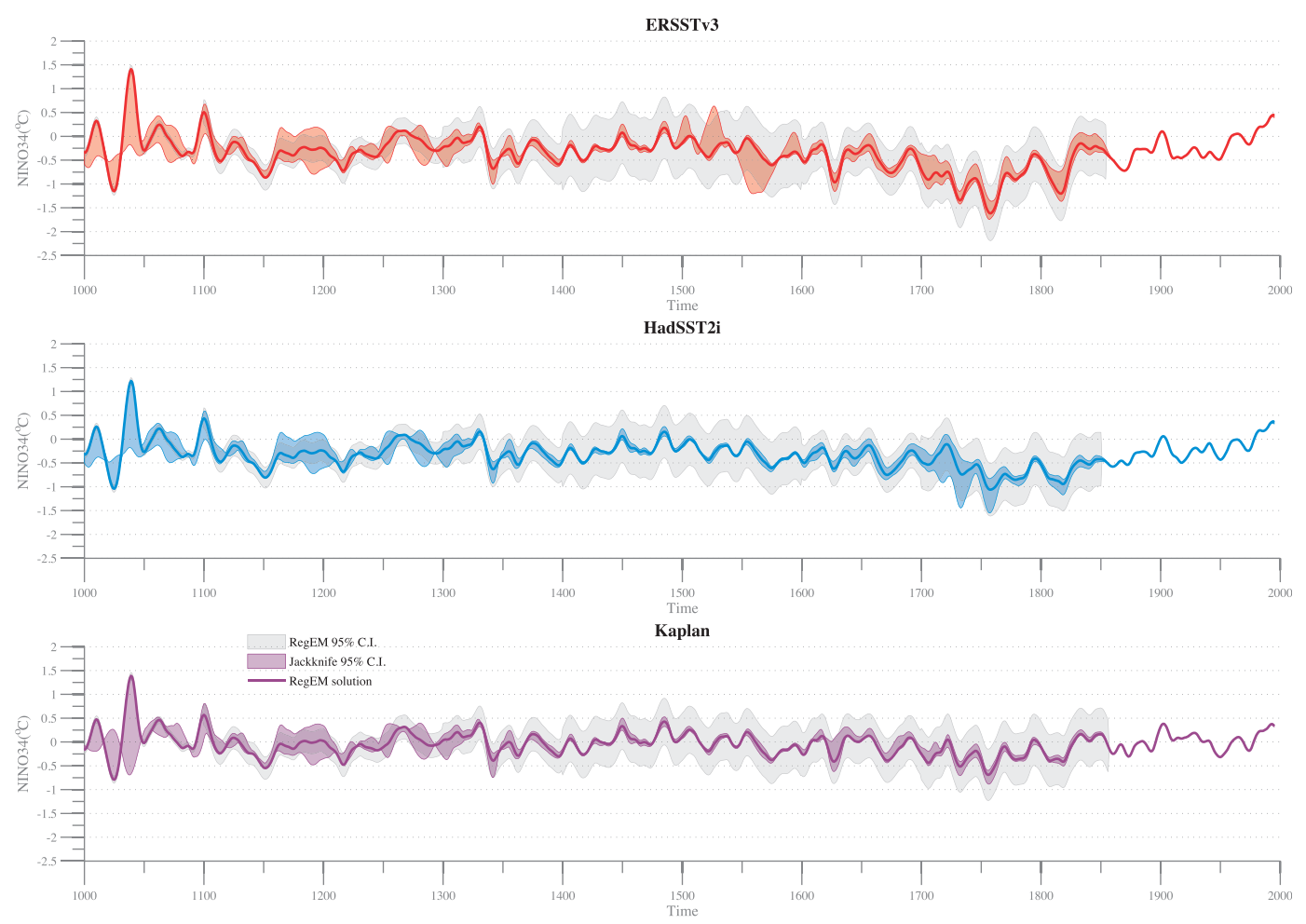

FIG. 8. Measures of uncertainty associated with LF RegEM reconstructions. Colored regions represent the spread of jackknife reconstructions; gray shaded regions represent RegEM-based confidence intervals.

\section{A millennial history of Niño-3.4 variability}

The average of all three RegEM TTLS reconstructions (hereafter "Avg") is presented in Fig. 11 (green curve) along with individual RegEM solutions. As expected, it is closest in character to the HadSST2i reconstruction, characterized by vigorous decadal variability throughout. The warmest point is reached at approximately A.D. $1490\left(+0.1^{\circ} \mathrm{C}\right)$ and the coldest point at approximately A.D. $1760\left(-0.14^{\circ} \mathrm{C}\right)$; that is, there is a range comparable to the width of RegEM confidence intervals, making it difficult to confidently reject the null hypothesis that tropical Pacific climate did not change on centennial scales. A comparison to recent reconstructions by M09 and W10 and to estimates of natural radiative forcing sheds light on key characteristics of tropical Pacific SST variability over the past $\sim 850$ years, which we then examine in the light of theories of the equatorial Pacific response to radiative forcing.

\section{a. Comparison to other ENSO reconstructions}

Several reconstructions of common ENSO indices have been previously published: the Southern Oscillation index (Stahle et al. 1998), coupled ENSO index (Gergis and Fowler 2005, 2006; Braganza et al. 2009), Niño-3 (D’Arrigo et al. 2005, M09), and Niño-3.4 (W10).
The latter two studies make use of the most recent proxy data and methodologies, so we compare our reconstructions to these indices. W10 carried out Niño-3.4 reconstructions using three networks: 1) one based on central Pacific corals ["center of action" (COA)], and 2) another based on proxies from teleconnected regions (TEL) and 3) tree-ring records from the Texas-Mexico region of North America (TEXMEX), which supersedes the Stahle et al. (1998) reconstruction. W10 generated several reconstructions for each network using various reconstruction techniques, which were subsequently averaged together to yield one composite reconstruction for each network (i.e., the effect of individual techniques was averaged out). In Fig. 11 we plot the TEL composite (orange curve), which covers the past $\sim 460$ years, as well as the M09 annual Niño-3 series (gray curve). M09 calibrated their reconstructions to HadSST2 while W10 calibrated theirs to the Hadley Centre Sea Ice and Sea Surface Temperature (HadISST) dataset (Rayner et al. 2003), which was subsequently high-pass filtered, yielding a near-zero trend. Finally, we plot the Palmyra coral series (the longest coral series with the highest signal-to-noise ratio in our network), scaled to Niño-3.4 units via a least squares fit over the A.D. 1898-1998 interval. All series have been 30-yr low-pass filtered for visual clarity. 


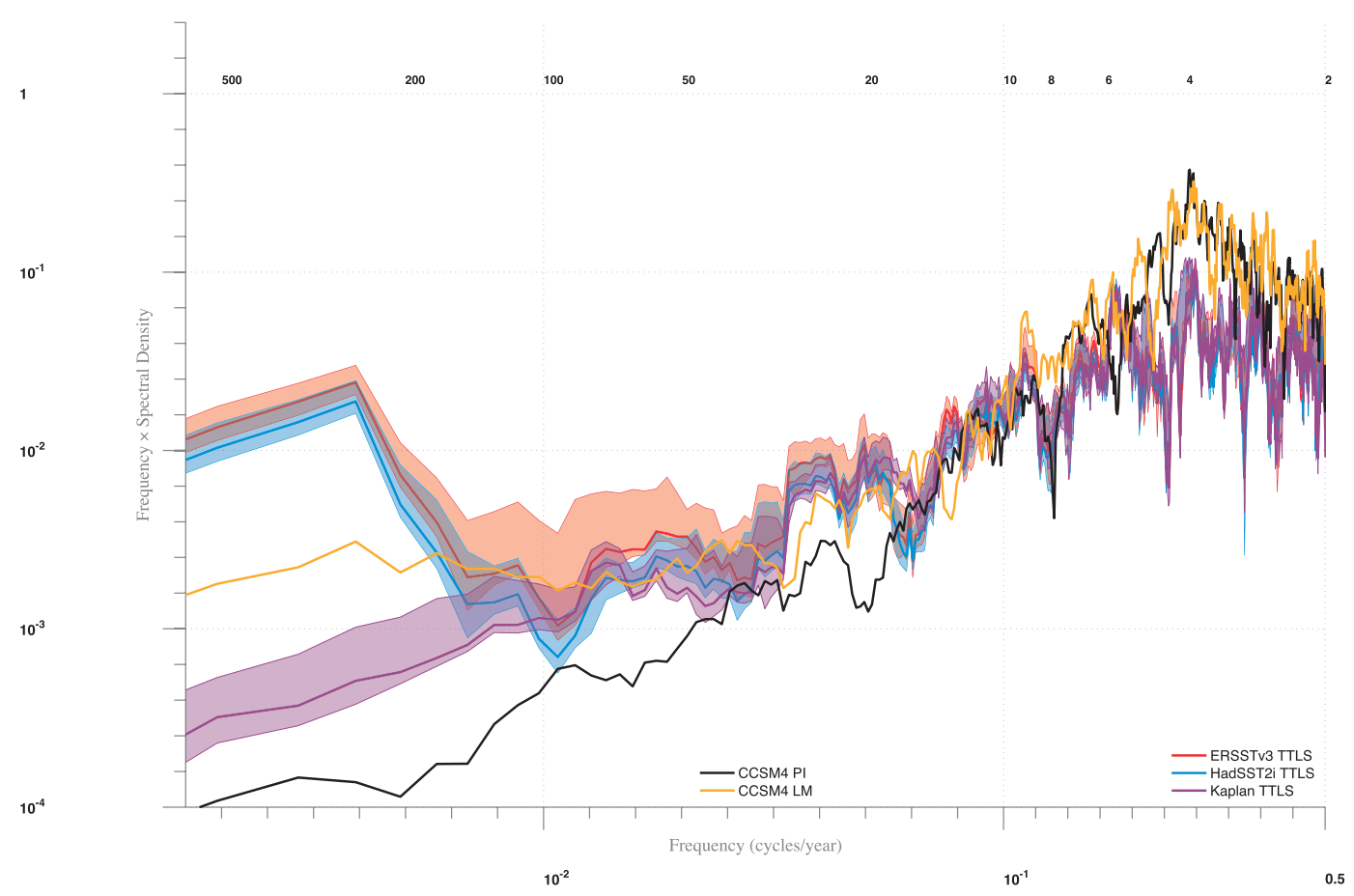

FIG. 9. Spectral characteristics of the 3 reconstructions. Variance-preserving spectra were obtained with the MTM (Thomson 1982) using a time-bandwidth product of 4, using data available after A.D. 1150. Numbers across the top indicate the period of oscillation in years and each color shaded region corresponds to jackknife ensembles for each target. Spectra are virtually identical if only post- A.D. 1300 data are used. (cf. Fig. 6 of Part I).

Before undertaking a comparison, one must be cognizant that the series plotted here do not always represent the same variables: indeed some target Niño-3 or Niño-3.4, either in annual or cold-season averages, the latter being sometimes defined as October-March or December-February. Nevertheless, all are meant to portray tropical Pacific climate during the past millennium, so should show some degree of similarity. While W10 displays oscillations around a flat baseline, the M09 reconstruction is marked by a millennium-long warming trend, upon which small-amplitude multidecadal fluctuations are superimposed. Our averaged reconstruction falls somewhere in between, with centennial variability comparable in amplitude to M09 and decadal variability comparable in amplitude to W10, but without the millennial warming trend seen in M09. Several excursions appear coincident in all reconstructions (e.g., relative minima around A.D. 1820 and 1610; relative maxima around A.D. 1840, A.D. 1790, and A.D. 1650), suggesting some degree of robustness. The Avg series is in relatively good agreement with the M09 series around A.D. 1520-1700 and after A.D. 1820; the two series are in starkest contrast around A.D. 1490-when M09 experiences its coldest temperature of the period, while Avg experiences its warmest-and before A.D. 1320, when M09 falls outside of the blue confidence interval.
What can explain such differences? The M09 Niño-3 index is diagnosed from a field that has been smoothed in state space because a decreasing number of SST modes are retained back in time to ensure appropriate regularization (M09; see their supplemental information). They write: "before 1600 the low-frequency component of the surface temperature reconstructions is described as a linear combination of just two leading patterns of temporal variation." Additionally, in using proxy data with decadal resolution for their low-frequency reconstruction, the M09 reconstruction is most accurate on interdecadal time scales. Our reconstructions, on the other hand, excluded decadally resolved proxies, which make a large part of the M09 signal. The multicentennial behavior of both reconstructions is otherwise compatible, given the large uncertainties.

Differences with the W10 TEL reconstruction arise at least in part because of their removing centennial variability from the target and coral proxies. In the spectral range where agreement can reasonably be expected between the TEL series and our average (periods from 10 to $50 \mathrm{yr}$ ), their correlation of 0.25 is rather low (because of phase differences across early fluctuations) but significant at the $95 \%$ level. The comparison to Palmyra $\delta^{18} \mathrm{O}$ shows decadal fluctuations in all three RegEM solutions (hence their average) to be directly driven by 


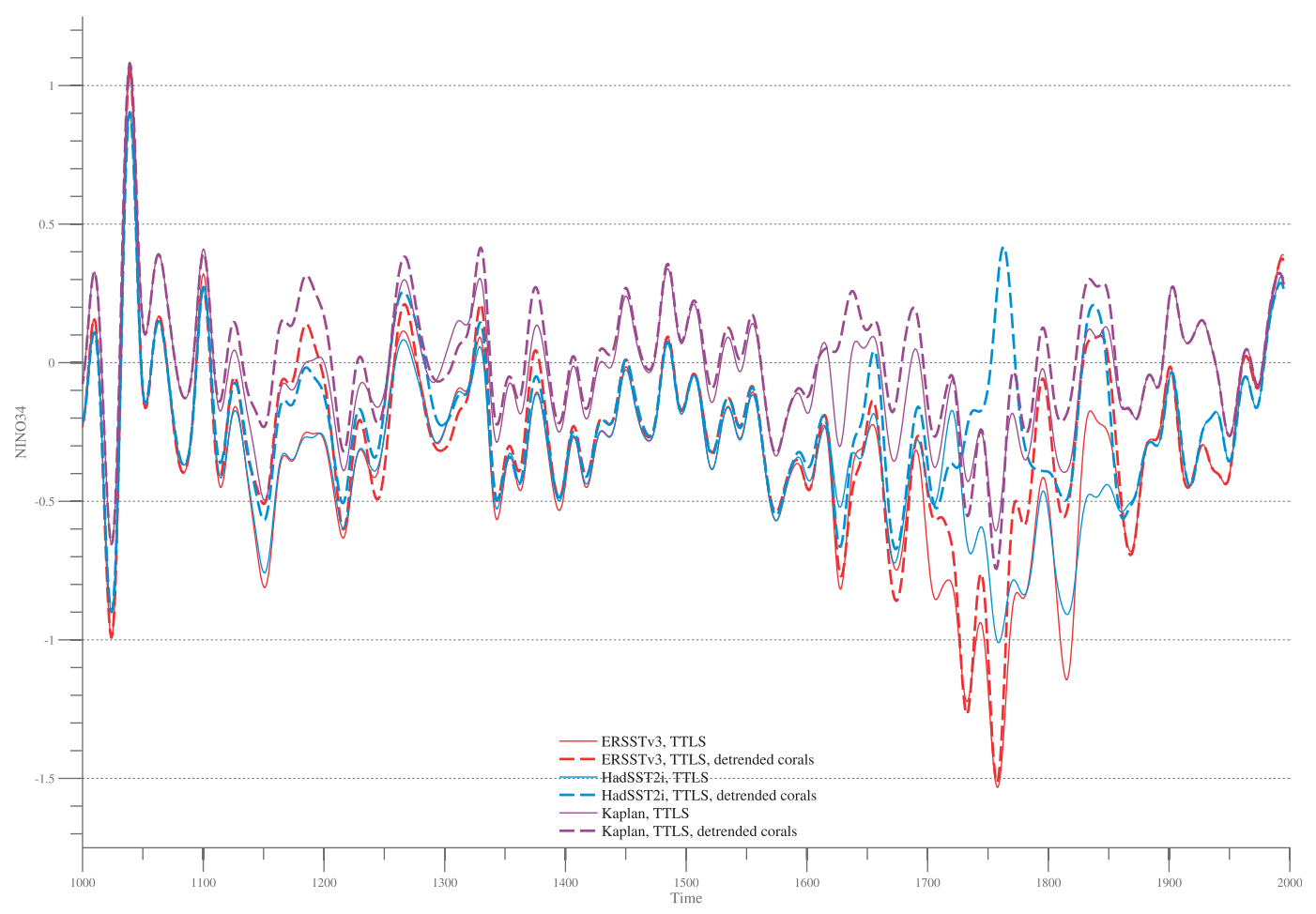

FIG. 10. Influence of coral detrending. Solid (dashed) lines depict reconstructions made from nondetrended corals (detrended coral records using a 150-yr spline fit; subscript $d$ ). Colors depict the instrumental target as before.

the $\delta^{18} \mathrm{O}$ swings before A.D. 1460. The longer-term changes in the mean, which suggest a rather cold MCA at Palmyra (in agreement with M09), do not translate into cold Niño-3.4 estimates around this time, due to discrepancies between the Palmyra coral and instrumental Niño-3.4 at LF, which result in a lower regression weight than for HF signals.

\section{b. Comparison to solar forcing}

In the past decade, several studies have suggested a link between natural radiative forcing (solar and volcanic) and ENSO, using methods either empirical (Adams et al. 2003) or numerical (Mann et al. 2005; Emile-Geay et al. 2007, 2008). As mentioned in the introduction, the core physical principle underlying such studies is the so-called ocean dynamical thermostat hypothesis (Clement et al. 1996), whereby changes in vertical heat advection-induced by the equatorial thermocline warming more slowly than equatorial SST and amplified by the Bjerknes feedback-act to counterbalance radiative heating in the eastern equatorial Pacific, thereby yielding a La Niña-like response (cold Niño-3.4) to increased radiative fluxes, and an El Niño-like response (warm Niño-3.4) to decreased radiative fluxes. This feedback has been shown to dominate within the model of Zebiak and Cane (1987) used in the aforementioned studies, but not in more comprehensive models that also include effects of SST changes on the atmospheric moisture budget and thermal stratification (e.g., Vecchi et al. 2006; McGregor and Timmermann 2011). Were the thermostat mechanism to dominate, one would expect decadal- to centennial-scale increases in solar irradiance to trigger a La Niña-like response with a phase lag of a decade or so, while 1-2-yr pulses of volcanic forcing should produce an opposite response within a year or two, with no memory thereafter. Here we test whether our Niño-3.4 reconstructions exhibit statistically significant responses to solar forcing over the past millennium, while our dating uncertainties preclude such a test of the volcanic response.

Solar magnetic activity, taken as a proxy for irradiance, displays well-documented Gleissberg $(\sim 88 \mathrm{yr})$ and DeVries ( 205 yr) cycles (Wagner et al. 2001; Peristykh and Damon 2003). Such activity can be reconstructed back in time from proxies of the atmospheric concentration of cosmogenic nuclides such as ${ }^{14} \mathrm{C}$ and ${ }^{10} \mathrm{Be}$. The estimates of Bard et al. (2007) and Steinhilber et al. (2009) are plotted in Fig. 12a. The Bard et al. (2007) series shows only minor differences with the original estimate of Bard et al. (2000), which was adapted by Crowley (2000) and used as forcing in the model experiments of Mann et al. (2005) and Emile-Geay et al. (2008). A more 


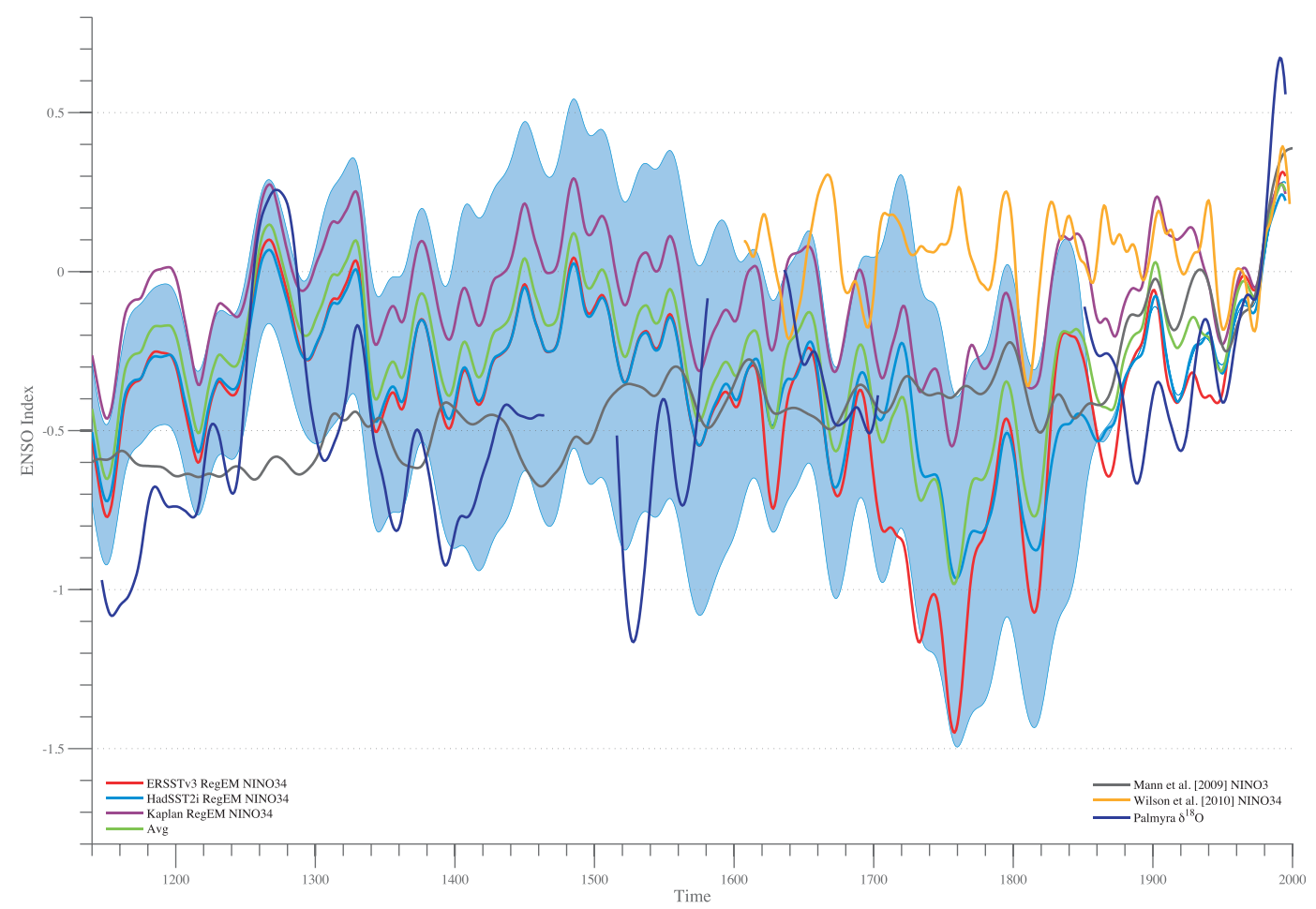

FIG. 11. Comparison of RegEM reconstructions to other notable ENSO reconstructions, showing TEL Niño-3.4 reconstruction from W10 (the longest available series from this study) and Niño-3 reconstruction from M09. All series have been 30-yr low-pass filtered for clarity. The blue shaded region corresponds to the RegEM-based measures of uncertainty from the HadSST2i TTLS reconstruction.

recent estimate of total solar irradiance over the Holocene was proposed by Steinhilber et al. (2009) via a combination of cosmogenic nuclide data and an observationally derived relationship between total solar irradiance and the open solar magnetic field. Both estimates are in close agreement as to the relative amplitude and timing of the major fluctuations at multidecadal and longer periods, though the peak-to-peak amplitude of the Steinhilber et al. (2009) forcing is about one-quarter that of Bard et al. (2007), who used the scaling of Lean et al. (1995), now considered to be an overestimate (Fröhlich and Lean 2004; Lean et al. 2005; Foukal et al. 2006). Multitaper method (MTM) spectral estimates (Fig. 12b) show that the forcings series only display significant cyclicities at periods longer than approximately $50 \mathrm{yr}$, particularly in a broadband peak around the $200-y r$ period. Neither signal shows a well-defined peak at the 88 -yr period, around which both estimates diverge markedly. To illustrate the relationship between solar forcing and the presumed Niño-3.4 response, we pick the Steinhilber et al. (2009) forcing and the Avg reconstruction defined earlier (Fig. 11, green curve) and unravel both signals using wavelet analysis (Torrence and Compo 1998) over the A.D. 1150-1961 period (chosen to maximize the reliability of our reconstruction and the overlap with the solar forcing series). The result is shown in Fig. 13. The averaged Niño-3.4 reconstruction shows sustained interannual (2-8 yr) variability throughout the entire interval, subject to important amplitude modulations. As discussed earlier, some intervals of subdued interannual variability could be partly due to dating uncertainties. The other salient feature is a high energy in the 200-250-yr spectral range (consistent with the Fig. 9 spectra). Is this energy consistent with forcing from a solar source?

To find out, we apply the methodology of Grinsted et al. (2004) (code available at http://noc.ac.uk/usingscience/crosswavelet-wavelet-coherence) to compute the cross-wavelet transform (which measures high common power in time-frequency space) and wavelet coherence (which is best thought of as a correlation coefficient in time-frequency space). Both are presented in Fig. 14, showing both high cross-wavelet power and high coherency near the 205-yr band (but remarkably, not the 88yr band), persisting throughout the entire analysis period. One can compute the average phase angle in the vicinity of the 205-yr period by averaging such angles over the $180-220-y r$ band. The result comes out to $-179^{\circ} \pm 29^{\circ}$, 

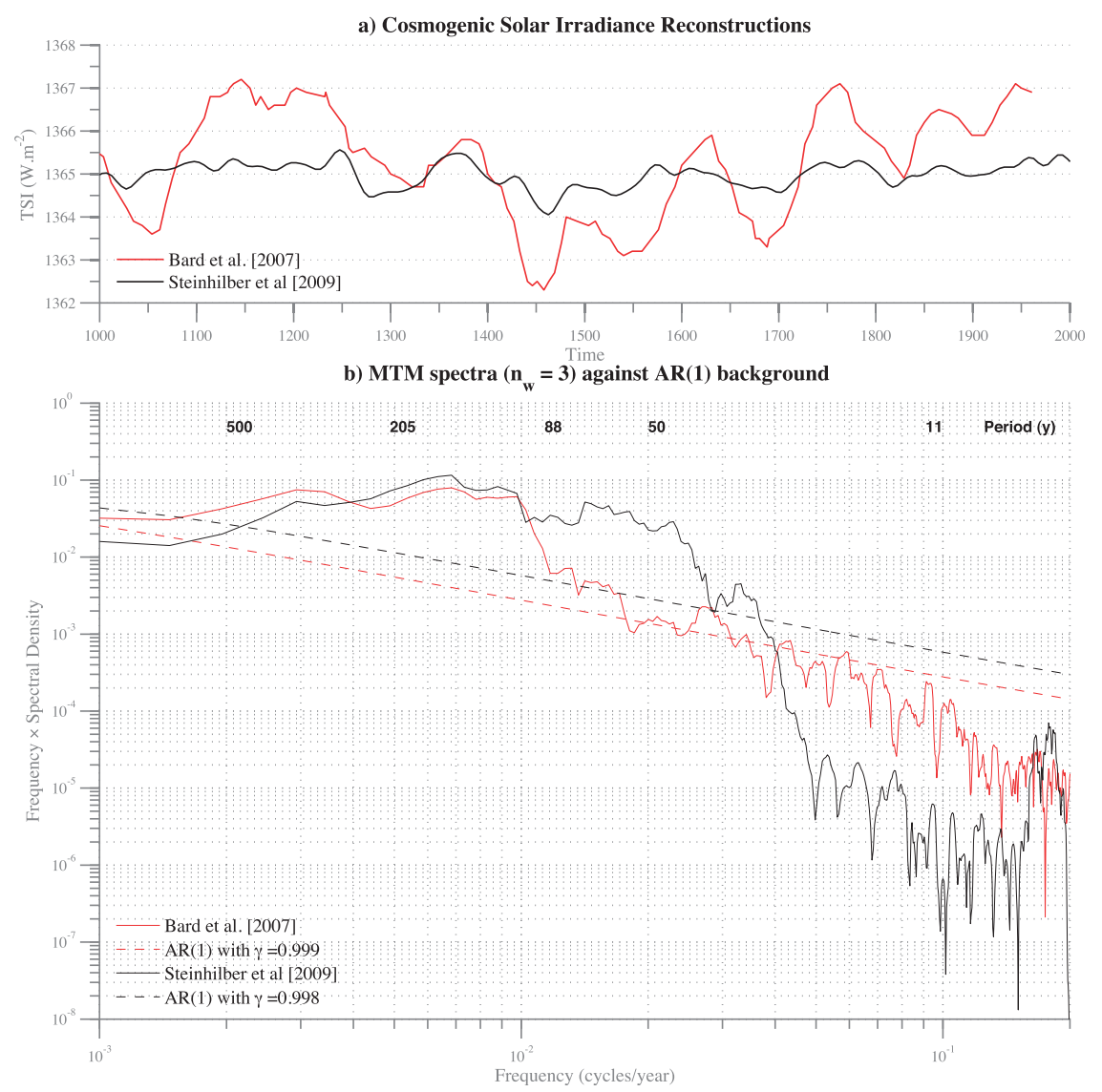

FIG. 12. Estimate of solar forcing histories over the past millennium. (a) Irradiance estimates from Bard et al. (2007) and the more recent estimate by Steinhilber et al. (2009). (b) Differences in scaling, though critical to the problem, are irrelevant to our estimate of correlations and phasing.

indicating an antiphased relationship with a subdecadal lag, in fair accordance with the predictions of the ocean dynamical thermostat hypothesis. The relatively small circular standard deviation of $29^{\circ}$ gives confidence in the reliability of this estimate.

Is this relationship an artifact of our choice of reconstruction method or solar forcing estimate? To further establish the robustness of this result, we bandpass filtered all four reconstructed Niño-3.4 series (three targets plus their average) for both reconstruction methods (CPS and RegEM TTLS) and two irradiance series in the 180220 -yr range before evaluating the linear correlation between them. Significance is assessed using the same nonparametric test used for screening predictors (which guards against the loss of degrees of freedom induced by the filtering operation). The results are shown in Table 2, revealing large anticorrelations, all significant and below -0.84 , for all estimates of Niño-3.4 and both forcings. The phase angles cluster around $-175^{\circ}$ with a circular standard deviation typically less than $30^{\circ}$, indicating consistent antiphased relationships.
It is surprising that this relationship, so apparent for the DeVries cycle, does not emerge for the Gleissberg cycle. One element of response is the weaker power in the 88-yr than the 205-yr band in both forcing histories, which may underestimate this cycle as documented elsewhere (Peristykh and Damon 2003). Finally, we find the antiphasing robust to the screening of predictors, but it is destroyed by coral detrending or the inclusion of some coarsely resolved records. Until confirmed by future studies, we must therefore leave open the possibility that the signal emerges as an artifact of our choice of data and methods.

\section{Discussion}

We have reconstructed the Niño-3.4 index using a network of accurately dated paleoclimate proxies back to A.D. 1000, using two largely independent methodologies, which were validated by systematic calibration/ verification exercises and (for RegEM) pseudoproxy studies (Part 1). Reconstructions showed some skill 

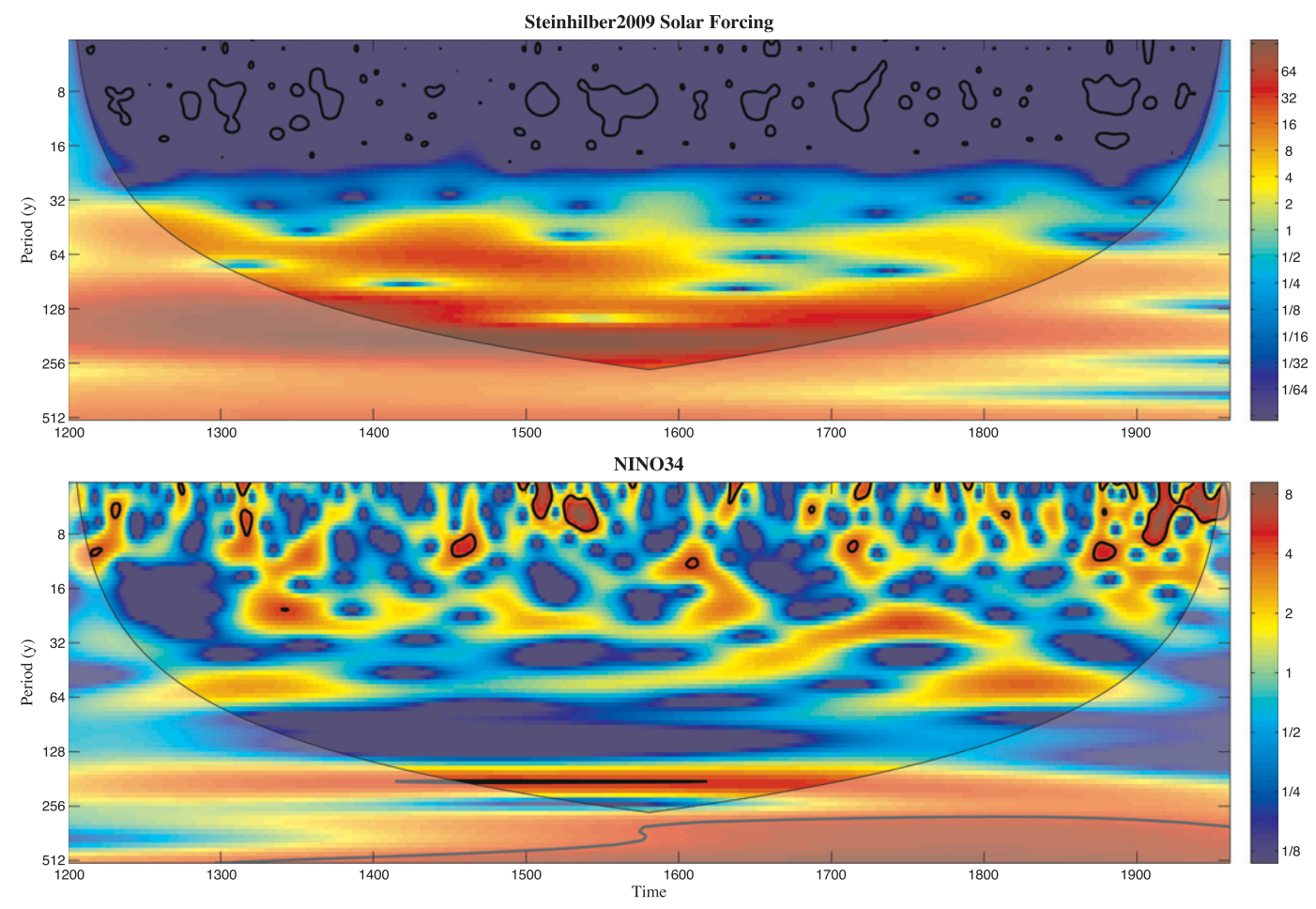

FIG. 13. Wavelet spectral density of (top) solar forcing (Steinhilber et al. 2009) and (bottom) reconstructed Niño3.4 (average of three RegEM TTLS solutions). The lighter shading denotes the cone of influence, indicating regions subject to damping by edge effects. Regions where variability exceeds that expected of a first-order autoregressive [AR(1)] process with the same lag-1 autocorrelation as each time series are enclosed by a black line. Colors represent wavelet spectral density in arbitrary units.

possible back to approximately A.D. 1300, although with substantial variance losses. We found the amplitude of interannual variability to be unevenly reduced back in time compared to the instrumental record, an artifact of dating uncertainties and the dwindling number of proxies before A.D. 1600 rather than a climatic feature. Overall, we found our reconstructions most trustworthy for LF variability (decadal and longer periods), whereas the approach of Li et al. (2011) (who used a homogenous, 1000-yr long, annually dated dataset) is better suited to the study of HF modulations over time.

Further, we probed the results' sensitivity to several key procedural choices, concluding that the centennial behavior of our solutions hinged most critically on the choice of target dataset. The dataset with the strongest instrumental Niño-3.4 trend (ERSSTv3) led to the most pronounced cooling around A.D. 1760, and vice versa for the dataset with the weakest instrumental trend (Kaplan). All three RegEM reconstructions agreed on a period of relative warmth about A.D. 1490 and disagreed on centennial variability after that date, but were otherwise in good agreement at decadal to multidecadal time scales. At such scales, our reconstructions showed amplitudes similar to the W10 TEL reconstruction, while at centennial scales they were closer in amplitude to the M09 reconstruction. Reconstruction methodologies (RegEM vs CPS) exhibit a secondary, but notable, impact on the estimated Niño-3.4 trajectories over the past millennium; this is a concern given the difficulty in discerning the best methodology (Part I). It is therefore essential to identify results that are robust to such choices and encourage continued improvements of climate reconstruction methodologies.

The notion of a La Niña-like change of the tropical Pacific climatology during the MCA (Seager et al. 2007; Graham et al. 2007) is qualitatively supported by a number of low-resolution sedimentary records (Rein et al. 2004; Turney and Palmer 2007; Helama et al. 2009), albeit with large dating uncertainties. Conversely, some studies have argued for an El Niño-like LIA (Cobb et al. 2003). None of our reconstructions lends support to these scenarios; in contrast, our reconstructions appear colder during the LIA than during the MCA, which is at odds with the aforementioned sedimentary records and the results of M09 (cf. Fig. 11). An alternate explanation is afforded by recent lake records documenting tropicswide hydrological changes (Conroy et al. 2009; Sachs et al.2009; Tierney et al.2010) over the past millennium, 

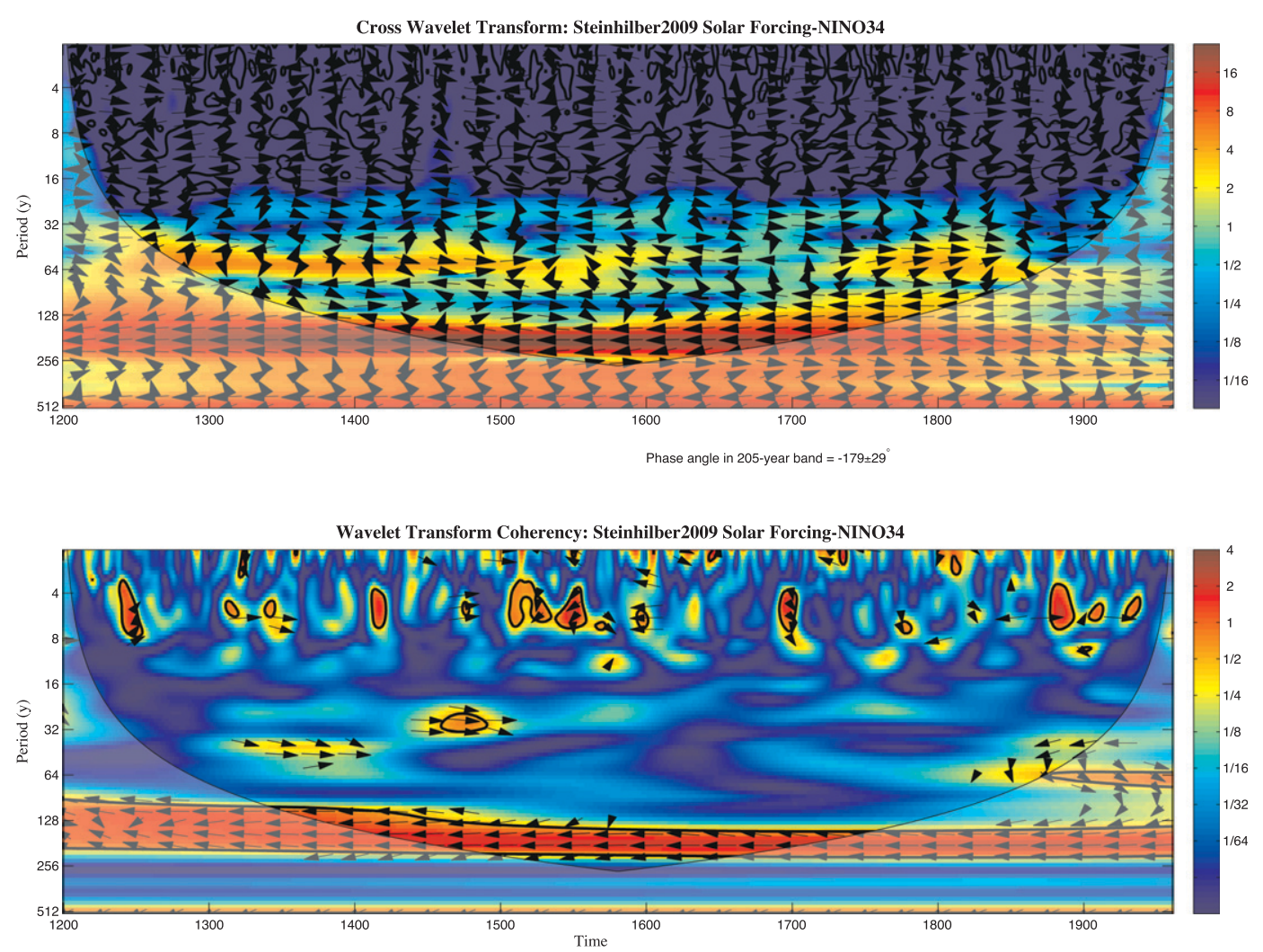

FIG. 14. Wavelet coherency analysis. (top) Cross-wavelet transform, indicating regions of high common power in time-scale space. (bottom) Wavelet transform coherency, measuring common power normalized by the underlying series' variance in a given time-scale region. Colors represent wavelet spectral density or coherency in arbitrary units. Regions where coherency exceeds that expected from the coherency between an AR(1) process of identical loworder moments such as Niño-3.4 and the solar irradiance reconstruction, are encircled by a black line. On both plots, arrows depict the phase of the Niño-3.4 signal with respect to the solar forcing. Arrows pointing to the left mean a phase angle close to $180^{\circ}$, indicating that episodes of high solar forcing tend to coincide with cold excursions in Niño3.4 SST.

which suggests that previous sedimentary records could be reinterpreted as consistent with warmer MCA SSTs in the eastern equatorial Pacific, partially obscured by large meridional excursions of the ITCZ. The causes of our discrepancies with M09 are potentially multiple: we used a different proxy dataset which excluded lowresolution sedimentary records, a different target index (Niño-3.4 vs Niño-3), a different target season (ours is December-March, theirs is annual), and a different statistical method (M09 used a climate field reconstruction, while we use single-index reconstruction methods). Systematic sensitivity studies will be needed to identify the origin of these differences.

In all cases investigated, spectral analysis revealed a more vigorous decadal to multidecadal variability throughout the past 850 years than suggested by W10, M09, or the two CGCM simulations (Fig. 9). What is the origin of this variability? The present results alone do not permit an attribution study. There is now ample evidence that decadal (10-30-yr scale) variability in tropical Pacific SST can arise without external forcingalthough its underlying mechanisms are still debated (Newman et al. 2003; Schneider and Cornuelle 2005; Vimont 2005; Di Lorenzo et al. 2010). In the Community Climate System Model, version 4.0 (CCSM4.0), it appears that this variability is rather subdued unless realistic boundary conditions are applied. The existence and origin of multidecadal to centennial (70-250-yr range) variability are more controversial still. The spectrum of Niño-3.4 reconstructions based on HadSST2i and ERSSTv3 targets (as well as the average) was found to be compatible with the forced CCSM4.0 simulation and incompatible with its control simulation. A wider array of simulations using fixed and varying boundary conditions, using a more representative sample of CGCMs, will be needed to complete this picture.

Another salient result concerns the relationship of Niño-3.4 with solar forcing. Assuming that the abundance 
TABLE 2. Bandpassed correlations of reconstructed Niño-3.4 with solar forcing estimates from two sources. Correlations significant at the $95 \%$ level [with respect to an ensemble of 1000 AR(1) processes with identical persistence as the target series] are denoted in boldface. The rightmost column reports the cross-wavelet transform phase angle (Grinsted et al. 2004) between the Steinhilber et al. (2009) forcing and the average of three Niño-3.4 reconstructions (Avg), together with its circular std dev. See text for details.

\begin{tabular}{|c|c|c|c|c|c|}
\hline \multirow{2}{*}{$\begin{array}{l}\text { Forcing } \\
\text { Method }\end{array}$} & \multicolumn{2}{|c|}{$\begin{array}{l}\text { Bard et al. } \\
\quad(2007)\end{array}$} & \multicolumn{2}{|c|}{$\begin{array}{l}\text { Steinhilber } \\
\text { et al. (2009) }\end{array}$} & \multirow{2}{*}{$\begin{array}{l}\text { Phase } \\
\text { angle }\end{array}$} \\
\hline & RegEM & CPS & RegEM & CPS & \\
\hline ERSSTv3 & -0.91 & -0.90 & -0.95 & -0.98 & $165^{\circ} \pm 27^{\circ}$ \\
\hline HadSST2i & -0.85 & -0.84 & -0.88 & -0.91 & $195^{\circ} \pm 50^{\circ}$ \\
\hline Kaplan SST & -0.95 & -0.89 & -0.99 & -0.97 & $178^{\circ} \pm 24^{\circ}$ \\
\hline Avg & -0.94 & $-\mathbf{0 . 8 9}$ & -0.98 & -0.97 & $181^{\circ} \pm 29^{\circ}$ \\
\hline
\end{tabular}

of cosmogenic isotopes provides a reliable estimate of past irradiance variations, and that our results provide a reliable estimate of tropical Pacific climate variability, this work supports the notion of cooler Niño-3.4 SST during centuries of high solar irradiance, broadly consistent with the ocean dynamical thermostat hypothesis (Clement et al. 1996; Mann et al. 2005). This result is also consistent with the study of Marchitto et al. (2010), who found a similar relationship to operate on millennial time scales, in accordance with the predictions of Emile-Geay et al. (2007). This contrasts with recent modeling results of DiNezio et al. $(2009,2010)$, who find the ocean dynamical thermostat to be subdued in most Intergovernmental Panel on Climate Change (IPCC)-class CGCMs on time scales longer than a few decades, where it is almost completely compensated by changes in the Pacific trade winds, linked to changes in the vertical profiles of atmospheric moisture and temperature forced by anthropogenic radiative perturbations (Knutson and Manabe 1995; Held and Soden 2006; Vecchi et al. 2006). If the reconstruction is correct that past Niño-3.4 SSTs have varied out of phase with solar irradiance on bicentennial scales, this could pose a new challenge both for CGCM simulations and for our understanding of the equatorial Pacific response to radiative forcing.

Several alternate hypotheses may offer resolutions to this conflict: 1) that cosmogenic isotopes reflect other influences (e.g., the geomagnetic field intensity); 2) that the proxy response to solar irradiance is not mediated by climate but by other, unidentified factors; 3) that our reconstructions do not reflect basinwide SST changes; 4) that the tropical Pacific response to solar forcing differs fundamentally from the response to anthropogenic forcing; and 5) that CGCMs misrepresent the relevant physics. The first possibility is unlikely because geomagnetic adjustments are thought to take place on multimillennial time scales (e.g., Beer 2000; Saint-Onge et al. 2003; Bard and Frank 2006; Muscheler et al. 2006; Gray et al. 2010). The main uncertainty lies therefore not in the timing but in the amplitude of past irradiance fluctuations, which are poorly constrained by calibrations to modern radiometric measurements (Foukal et al. 2004; Fröhlich and Lean 2004; Foukal et al. 2006), presenting a major challenge to an estimate of the climate sensitivity to solar forcing fluctuations. Thus, although our statistical analysis is independent of the estimated amplitude of solar forcing, it is clear that the weaker the forcing, the harder it might be to establish a plausible physical mechanism whereby it might have influenced Niño-3.4 SST, or might continue to do so in the future. The second possibility has not been borne out by any proxy studies: to the best of our knowledge there is no published evidence of a relationship between irradiance variations and proxy responses that does not involve climate. The third possibility is a more serious objection: the ocean dynamical thermostat is associated with changes in zonal SST gradients, which single-index reconstructions are obviously unable to resolve. If irradiance increases, most of the globe would probably warm; therefore, to be consistent with the ocean dynamical thermostat hypothesis, any cooling in Niño-3.4 must be accompanied by enhanced zonal and meridional SST gradients. So while it is difficult to imagine a scenario in which cooler Niño-3.4 SSTs in a generally warmer tropical Pacific would not be associated with an enhanced zonal gradient, the possibility cannot be excluded until additional proxy evidence (or a reinterpretation of existing records) from western $\mathrm{Pa}-$ cific and off-equatorial locations becomes available.

The fourth possibility (solar and anthropogenic forcing differ fundamentally) is supported by several lines of evidence. Meehl et al. (2003) outline three key differences between the two types of forcings: 1) solar forcing is only active during the day, while the longwave portion of anthropogenic forcing acts at night as well; 2) solar forcing is spatially heterogeneous, while greenhouse gas forcing is more spatially uniform; and 3) solar forcing occurs principally in the UV and shortwave domains, while anthropogenic forcing affects both the longwave and shortwave domains. In addition, recent work has shown the upper tropical Pacific Ocean heat and momentum budgets to be exquisitely sensitive to the vertical distribution of visible light absorption (Anderson et al. 2009; Jochum et al. 2010), while no such symmetrybreaking effect exists for greenhouse forcing in the ocean. There are therefore at least four distinct physical reasons to expect a different response to anthropogenic and solar forcing.

Finally, the last possibility (deficient models) cannot be excluded either: the upper ocean heat budget is 
maintained by a delicate balance of mutually opposing physical processes, many of which occur at the subgrid scale and must therefore be parameterized; any small inaccuracy in the representation of such processes may therefore tip a CGCM's behavior into one direction or another, as exemplified by the considerable spread between projections of tropical Pacific climate under continued anthropogenic forcing (Yamaguchi and Noda 2006; Meehl et al. 2007; Collins et al. 2010; Vecchi and Wittenberg 2010). A clear antiphasing between Niño-3.4 SST and solar forcing on bicentennial time scales may therefore represent a key constraint for the ability of CGCMs to correctly simulate the tropical Pacific response to external forcing.

There are important limitations to our approach. First, the dearth of proxy data from the Niño-3.4 region itself (cf. Fig. 2) compels us to use data from teleconnected regions. Although this is physically justifiable, it would be preferable to use proxy records from more proximal locations, less susceptible to slow changes in teleconnection patterns. Efforts to expand the temporal coverage and the reproducibility of the Palmyra fossil coral reconstruction are currently underway and similar efforts by the proxy community must be prioritized. Most importantly, an estimate of tropical SST that no longer relies on terrestrial records will permit a truly independent test of the hypothesis that medieval megadroughts were caused by cold conditions in the eastern tropical Pacific (Seager et al. 2007; Graham et al. 2007), a test that is impossible at present. In the meantime, it is also important to test the validity of the constant teleconnections hypothesis in GCMs (e.g., Sterl et al. 2007). Second, our RegEM methodology rests on the assumption that preinstrumental climate values are missing at random (i.e., the probability of a point being missing is independent of the value at that point), which is difficult to justify in the context of long-term trends. Pseudoproxy tests, however, provide a heuristic justification for his approximation (Part I). Third, one may object to our estimates of uncertainty. Bayesian hierarchical methods (e.g., Tingley and Huybers 2010a,b; Tingley et al. 2012) should enable a more comprehensive quantification of errors in climate reconstructions, but the methods proposed to date are not yet suitable for use with teleconnected proxy data. An advantage of our jackknife and GCV approaches lies in their simplicity, which facilitates their interpretation, but gives no guarantee of conveying the full uncertainty. Fourth, the validation step of the reconstruction is itself a much-debated topic (Bürger 2007; Mann et al. 2007). The pseudoproxy framework offers the most comprehensive test bed for such methods, but still awaits a realistic description of the strengths and weaknesses inherent to each proxy class (Cobb et al. 2008; Jones et al. 2009). The use of process-based proxy models, incorporating physical, chemical, and biological mechanisms of proxy genesis, is a promising route toward that objective (Anchukaitis et al. 2006; Evans 2007; Cobb et al. 2008; Thompson et al. 2011; Mann et al. 2012). Finally, our reconstructions are only reliable since approximately A.D. 1300 , which means that fewer than four 200-yrlong cycles can be reliably identified. That is a small sample size to establish the significance of the solarNiño-3.4 antiphasing, and will require confirmation from records spanning the Common Era and beyond.

\section{Conclusions}

In summary, this multiproxy Niño-3.4 reconstruction effort supports three main conclusions:

1) Given the current proxy network, a surprising result is that discrepancies between historical SST analyses are a key obstacle to a more accurate estimate of tropical Pacific SST variability in preinstrumental times. Ironically, then, a priority for improving multiproxy reconstruction of tropical Pacific climate over the last millennium lies in reducing uncertainties in SST estimates since A.D. 1850. Three parallel avenues can usefully contribute to this goal: (i) continuing efforts in ship data digitization, homogenization, and bias correction, as well as a consistent treatment of associated uncertainties (e.g., Kennedy et al. 2011a; Kennedy et al. 2011b); (ii) improving statistical methods for spatiotemporal imputation and enabling their intercomparison on synthetic datasets; and (iii) expanding the number of high-resolution proxy records that span the last 150 years, rather than an exclusive focus on records that extend beyond the instrumental record, as is common practice at present.

2) Despite inevitable variance losses due to proxy data sparsity, our best estimates of Niño-3.4 since A.D. 1150 suggest vigorous decadal to multidecadal variability in the tropical Pacific system, much higher than is present in the two CGCM simulations analyzed here. This feature may prove an important test for CGCMs, either in a forced or unforced context. However, the estimated long-term (centennial) variability is still quite uncertain and, as emphasized above, fundamentally limited by the quality of the instrumental SST record and the accuracy of current reconstruction methods.

3) We find no evidence for a systematic change in Niño3.4 corresponding to the LIA or MCA. However, Niño-3.4 exhibited a strong and persistent antiphased relationship with solar forcing closely aligned with 
the 205-yr (DeVries) cycle. This result is robust to most methodological considerations investigated and is broadly consistent with the ocean thermostat hypothesis (Clement et al. 1996). Interestingly, however, this antiphase relationship is not apparent at subcentennial time scales in our reconstruction. While the thermostat concept may be ill suited to the description of twenty-first-century climate evolution under continued anthropogenic forcing (DiNezio et al. 2009, 2010), the possibility remains that it shaped LF tropical Pacific climate change before the anthropogenic era. Progress on this question is most pressing: whether or not the tropical Pacific climate responded consistently to natural radiative forcing in the recent past bears directly on the question of its real-world sensitivity to anthropogenic climate change. Therefore, this knowledge could directly impact our ability to predict global and regional climate variability over the coming century.

Acknowledgments. We acknowledge funding from NOAA Grant NA06OAR4310116. The authors thank Scott Rutherford, Emanuele DiLorenzo, Judith Curry, Kettyah Chaak, Tapio Schneider, Julie Richey, David Black, Kevin Anchukaitis, Paige Green, and Glenn Alexander for providing data, help, and support. Data and code are available online at http://hurricane.ncdc. noaa.gov/pls/paleox/f?p=519:1:4253936273493430::.::P1_ STUDY_ID:13684.

\section{REFERENCES}

Adams, J., M. Mann, and C. Ammann, 2003: Proxy evidence for an El Niño-like response to volcanic forcing. Nature, 426, 274 278, doi:10.1038/nature02101.

Ammann, C. M., F. Joos, D. S. Schimel, B. L. Otto-Bliesner, and R. A. Tomas, 2007: Solar influence on climate during the past millennium: Results from transient simulations with the NCAR Climate System Model. Proc. Natl. Acad. Sci USA, 104, 3713-3718, doi:10.1073/pnas.0605064103.

Anchukaitis, K. J., M. N. Evans, A. Kaplan, E. A. Vaganov, M. K. Hughes, H. D. Grissino-Mayer, and M. A. Cane, 2006: Forward modeling of regional scale tree-ring patterns in the southeastern United States and the recent influence of summer drought. Geophys. Res. Lett., 33, L04705, doi:10.1029/ 2005GL025050.

Anderson, W., A. Gnanadesikan, and A. Wittenberg, 2009: Regional impacts of ocean color on tropical Pacific variability. Ocean Sci., 5, 313-327.

Ault, T. R., J. E. Cole, M. N. Evans, H. Barnett, N. J. Abram, A. W. Tudhope, and B. K. Linsley, 2009: Intensified decadal variability in tropical climate during the late 19th century. Geophys. Res. Lett., 36, L08602, doi:10.1029/2008GL036924.

Bard, E., and M. Frank, 2006: Climate change and solar variability: What's new under the sun? Earth Planet. Sci. Lett., 248, $1-14$.
, G. Raisbeck, F. Yiou, and J. Jouzel, 2000: Solar irradiance during the last 1200 years based on cosmogenic nuclides. Tellus, 52B, 985-992.

,,--- , and -2007 : Comment on "Solar activity during the last $1000 \mathrm{yr}$ inferred from radionuclide records" by Muscheler et al. (2007). Quat. Sci. Rev., 26, 2301-2304, doi:10.1016/j.quascirev.2007.06.002.

Beer, J., 2000: Long-term indirect indices of solar variability. Space Sci. Rev., 94, 53-66.

Bjerknes, J., 1969: Atmospheric teleconnections from the equatorial Pacific. Mon. Wea. Rev., 97, 163-172.

Bradley, R. S., and P. D. Jones, 1993: "Little Ice Age" summer temperature variations: Their nature and relevance to recent global warming trends. Holocene, 3, 367-376, doi: 10.1177/ 095968369300300409.

Braganza, K., J. L. Gergis, S. B. Power, J. S. Risbey, and A. M. Fowler, 2009: A multiproxy index of the El Niño-Southern Oscillation, A.D. 1525-1982. J. Geophys. Res., 114, D05106, doi:10.1029/2008JD010896.

Bürger, G., 2007: On the verification of climate reconstructions. Climate Past, 3, 397-409.

Capotondi, A., A. Wittenberg, and S. Masina, 2006: Spatial and temporal structure of tropical Pacific interannual variability in 20th century coupled simulations. Ocean Modell., 15, 274298.

Clement, A. C., R. Seager, M. A. Cane, and S. E. Zebiak, 1996: An ocean dynamical thermostat. J. Climate, 9, 2190-2196.

Cobb, K. M., C. D. Charles, H. Cheng, and R. L. Edwards, 2003: El Niño/Southern Oscillation and tropical Pacific climate during the last millennium. Nature, 424, 271-276.

— T. Kiefer, J. M. Lough, J. T. Overpeck, and A. W. Tudhope, 2008: Final report: Representing and reducing uncertainties in high-resolution climate proxy data. Tech. Rep., 20 pp. [Available online at http://www.ncdc.noaa.gov/paleo/reports/ trieste2008/trieste2008final.pdf.]

Collins, M., and Coauthors, 2010: The impact of global warming on the tropical Pacific Ocean and El Niño. Nat. Geosci., 3, 391397, doi:10.1038/ngeo868.

Conroy, J. L., A. Restrepo, J. T. Overpeck, M. Steinitz-Kannan, J. E. Cole, M. B. Bush, and P. A. Colinvaux, 2009: Unprecedented recent warming of surface temperatures in the eastern tropical Pacific Ocean. Nat. Geosci., 2, 46-50, doi:10.1038/ngeo390.

Cook, E. R., cited, 2008: North American summer PDSI reconstructions, version 2a. NOAA/NGDC Paleoclimatology Program. [Available online at http://gcmd.nasa.gov/ KeywordSearch/Metadata.do?Portal=GCMD\&KeywordPath $=$ Parameters|CLIMATE+INDICATORS|DROUGHT\% 2FPRECIPITATION+INDICES|PALMER+DROUGHT+ SEVERITY + INDEX\&EntryId=NOAA_NCDC_PALEO_ 2004-045\&MetadataView $=$ Full $\&$ MetadataType $=0 \& 1$ bnode $=$ mdlb3.]

- C. A. Woodhouse, C. M. Eakin, D. M. Meko, and D. W. Stahle, 2004: Long-term aridity changes in the western United States. Science, 306, 1015-1018, doi:10.1126/science.1102586.

, K. J. Anchukaitis, B. M. Buckley, R. D. D'Arrigo, G. C. Jacoby, and W. E. Wright, 2010: Asian monsoon failure and megadrought during the last millennium. Science, 328, 486489, doi:10.1126/science. 1185188 .

Crowley, T. J., 2000: Causes of climate change over the past 1000 years. Science, 289, 270-277.

D’Arrigo, R., E. R. Cook, R. J. Wilson, R. Allan, and M. E. Mann, 2005: On the variability of ENSO over the past six centuries. Geophys. Res. Lett., 32, L03711, doi:10.1029/2004GL022055. 
Dean, J. S., and D. E. Doyel, 2006: Culture, environment, and adaptation: Perspectives from the ancient Southwest. Environmental Change and Human Adaptation in the Ancient American Southwest, D. E. Doyel and J. S. Dean, Eds., University of Utah Press, 1-9.

Deser, C., A. S. Phillips, and M. A. Alexander, 2010: Twentieth century tropical sea surface temperature trends revisited. Geophys. Res. Lett., 37, L10710, doi:10.1029/2010GL043321.

Di Lorenzo, E., K. M. Cobb, J. C. Furtado, N. Schneider, B. T. Anderson, A. Bracco, M. A. Alexander, and D. J. Vimont, 2010: Central Pacific El Niño and decadal climate change in the North Pacific Ocean. Nat. Geosci., 3, 762-765, doi:10.1038/ngeo984.

DiNezio, P. N., A. C. Clement, G. A. Vecchi, B. J. Soden, B. P. Kirtman, and S.-K. Lee, 2009: Climate response of the equatorial Pacific to global warming. J. Climate, 22, 4873-4892.

,-- , and -2010 : Reconciling differing views of tropical Pacific climate change. Eos, Trans. Amer. Geophys. Union, 91, 141-142.

Efron, B., 1981: Nonparametric estimates of standard error: The jackknife, the bootstrap and other methods. Biometrika, 68, 589-599.

Emile-Geay, J., M. Cane, R. Seager, A. Kaplan, and P. Almasi, 2007: El Niño as a mediator of the solar influence on climate. Paleoceanography, 22, PA3210, doi:10.1029/2006PA001304.

_- R. Seager, M. Cane, E. Cook, and G. H. Haug, 2008: Volcanoes and ENSO over the past millennium. J. Climate, 21, 3134-3148.

— K. Kobb, M. Mann, and A. T. Wittenberg, 2013: Estimating tropical Pacific SST variability over the past millennium. Part I: Methodology and validation. J. Climate, 26, 2302-2328.

Esper, J., E. R. Cook, and F. H. Schweingruber, 2002: Lowfrequency signals in long tree-ring chronologies for reconstructing past temperature variability. Science, 295, 2250-2253.

Evans, M. N., 2007: Toward forward modeling for paleoclimatic proxy signal calibration: A case study with oxygen isotopic composition of tropical woods. Geochem. Geophys. Geosyst., 8, Q07008, doi:10.1029/2006GC001406.

Felis, T., J. Pätzold, Y. Loya, M. Fine, A. H. Nawar, and G. Wefer, 2000: A coral oxygen isotope record from the northern Red Sea documenting NAO, ENSO, and North Pacific teleconnections on Middle East climate variability since the year 1750. Paleoceanography, 15, 679-694.

Fierro, R. D., G. H. Golub, P. C. Hansen, and D. P. O'Leary, 1997: Regularization by truncated total least squares. SIAM J. Sci. Comput., 18, 1223-1241.

Foukal, P., G. North, and T. Wigley, 2004: A stellar view on solar variations and climate. Science, 306, 68-69.

—, C. Fröhlich, H. Spruit, and T. M. L. Wigley, 2006: Variations in solar luminosity and their effect on the Earth's climate. Nature, 443, 161-166, doi:10.1038/nature05072.

Fröhlich, C., and J. Lean, 2004: Solar radiative output and its variability: Evidence and mechanisms. Astron. Astrophys. Rev., 12, 273-320.

Frost, C., and S. G. Thompson, 2000: Correcting for regression dilution bias: Comparison of methods for a single predictor variable. J. Roy. Stat. Soc., 163A, 173-189, doi:10.1111/ 1467-985X.00164.

Fye, F. K., D. W. Stahle, and E. R. Cook, 2003: Paleoclimatic analogs to twentieth-century moisture regimes across the United States. Bull. Amer. Meteor. Soc., 84, 901-909.

Gergis, J., and A. Fowler, 2005: Classification of synchronous oceanic and atmospheric El Niño-Southern Oscillation
(ENSO) events for palaeoclimate reconstruction. Int. J. Climatol., 25, 1541-1565.

, and - 2006: How unusual was late 20th century El NiñoSouthern Oscillation (ENSO)? Assessing evidence from treering, coral, ice-core and documentary palaeoarchives, A.D. 1525-2002. Adv. Geosci., 6, 173-179.

Graham, N. E., and Coauthors, 2007: Tropical Pacific-mid-latitude teleconnections in medieval times. Climatic Change, 83, 241285, doi:10.1007/s10584-007-9239-2.

_ C. Ammann, D. Fleitmann, K. Cobb, and J. Luterbacher, 2011: Support for global climate reorganization during the "medieval climate anomaly." Climate Dyn., 37, 1217-1245, doi:10.1007/s00382-010-0914-z.

Gray, L. J., and Coauthors, 2010: Solar influences on climate. Rev. Geophys., 48, RG4001, doi:10.1029/2009RG000282.

Grinsted, A., J. C. Moore, and S. Jevrejeva, 2004: Application of the cross wavelet transform and wavelet coherence to geophysical time series. Nonlinear Processes Geophys., 11, 561566.

Guilyardi, E., A. Wittenberg, A. Fedorov, M. Collins, C. Wang, A. Capotondi, G. J. van Oldenborgh, and T. Stockdale, 2009: Understanding El Niño in ocean-atmosphere general circulation models: Progress and challenges. Bull. Amer. Meteor. Soc., 90, 325-340.

Helama, S., J. Merilainen, and H. Tuomenvirta, 2009: Multicentennial megadrought in northern Europe coincided with a global El Niño-Southern Oscillation drought pattern during the Medieval Climate Anomaly. Geology, 37, 175-178, doi:10.1130/G25329A.1.

Held, I. M., and B. J. Soden, 2006: Robust responses of the hydrological cycle to global warming. J. Climate, 19, 5686-5699.

Hendy, E. J., M. K. Gagan, C. A. Alibert, M. T. McCulloch, J. M. Lough, and P. J. Isdale, 2002: Abrupt decrease in tropical Pacific sea surface salinity at end of Little Ice Age. Science, 295, 1511-1514, doi:10.1126/science.1067693.

Herweijer, C., R. Seager, E. Cook, and J. Emile-Geay, 2007: North American droughts of the last millennium from a gridded network of tree-ring data. J. Climate, 20, 1353-1376.

ITRDB, cited 2009: Tree ring database. International Tree-Ring Data Bank. [Available online at http://www.ncdc.noaa.gov/ paleo/treering.html.]

Jochum, M., S. Yeager, K. Lindsay, K. Moore, and R. Murtugudde, 2010: Quantification of the feedback between phytoplankton and ENSO in the Community Climate System Model. J. Climate, 23, 2916-2925.

Jones, P., and M. Mann, 2004: Climate over past millennia. Rev. Geophys., 42, RG2002, doi:10.1029/2003RG000143.

- and Coauthors, 2009: High-resolution palaeoclimatology of the last millennium: A review of current status and future prospects. Holocene, 19, 3-49, doi:10.1177/0959683608098952.

Kaplan, A., Y. Kushnir, M. A. Cane, and M. B. Blumenthal, 1997: Reduced space optimal analysis for historical data sets: 136 years of Atlantic sea surface temperatures. J. Geophys. Res., 102 (C13), 27 835-27 860.

Karnauskas, K. B., R. Seager, A. Kaplan, Y. Kushnir, and M. A. Cane, 2009: Observed strengthening of the zonal sea surface temperature gradient across the equatorial Pacific Ocean. J. Climate, 22, 4316-4321.

Kennedy, J. J., N. A. Rayner, R. O. Smith, D. E. Parker, and M. Saunby, 2011a: Reassessing biases and other uncertainties in sea surface temperature observations measured in situ since 1850: 1. Measurement and sampling uncertainties. J. Geophys. Res., 116, D14103, doi:10.1029/2010JD015218. 
,,,--- , and,$- 2011 \mathrm{~b}$ : Reassessing biases and other uncertainties in sea surface temperature observations measured in situ since 1850: 2. Biases and homogenization. J. Geophys. Res., 116, D14104, doi:10.1029/2010JD015220.

Khider, D., L. D. Stott, J. Emile-Geay, R. Thunell, and D. Hammond, 2011: Assessing El Niño-Southern Oscillation variability during the past millennium. Paleoceanography, 26, PA3222, doi:10.1029/2011PA002139.

Kim, D., J.-S. Kug, I.-S. Kang, F.-F. Jin, and A. Wittenberg, 2008: Tropical Pacific impacts of convective momentum transport in the SNU coupled GCM. Climate Dyn., 31, 213-226, doi:10.1007/s00382-007-0348-4.

Knutson, T. R., and S. Manabe, 1995: Time-mean response over the tropical Pacific to increased $\mathrm{CO}_{2}$ in a coupled oceanatmosphere model. J. Climate, 8, 2181-2199.

Lean, J., J. Beer, and R. Bradley, 1995: Reconstruction of solar irradiance since 1610: Implications for climate change. Geophys. Res. Lett., 22, 3195-3198, doi:10.1029/95GL03093.

_ , G. Rottman, J. Harder, and G. Kopp, 2005: SORCE contributions to new understanding of global change and solar variability. Sol. Phys., 230, 27-53, doi:10.1007/s11207005-1527-2.

Leiberman, V., 2003: Integration on the Mainland. Vol. 1, Strange Parallels: Southeast Asia in Global Context, c. 800-1830, Cambridge University Press, 508 pp.

Le Quesne, C., D. W. Stahle, M. K. Cleaveland, M. D. Therrell, J. C. Aravena, and J. Barichivich, 2006: Ancient Austrocedrus tree-ring chronologies used to reconstruct central Chile precipitation variability from A.D. 1200 to 2000. J. Climate, 19, 5731-5744.

Li, B., D. W. Nychka, and C. M. Ammann, 2010: The value of multi-proxy reconstruction of past climate. J. Amer. Stat. Assoc., 105, 883-911.

Li, J., S.-P. Xie, E. R. Cook, G. Huang, R. D'Arrigo, F. Liu, J. Ma, and X.-T. Zheng, 2011: Interdecadal modulation of El Niño amplitude during the past millennium. Nat. Climate Change, $\mathbf{1}$, 114-118.

Liu, Z., 1998: The role of ocean in the response of tropical climatology to global warming: The west-east SST contrast. J. Climate, 11, 864-875.

Mann, M. E., 2002: Climate reconstruction: The value of multiple proxies. Science, 297, 1481-1482, doi:10.1126/science.1074318.

_ , M. A. Cane, S. E. Zebiak, and A. Clement, 2005: Volcanic and solar forcing of the tropical Pacific over the past 1000 years. J. Climate, 18, 447-456.

—, S. Rutherford, E. Wahl, and C. Ammann, 2007: Robustness of proxy-based climate field reconstruction methods. J. Geophys. Res., 112, D12109, doi:10.1029/2006JD008272.

—, Z. Zhang, M. K. Hughes, R. S. Bradley, S. K. Miller, S. Rutherford, and F. Ni, 2008: Proxy-based reconstructions of hemispheric and global surface temperature variations over the past two millennia. Proc. Natl. Acad. Sci. USA, 105, 13 252-13 257, doi:10.1073/pnas.0805721105.

— gins of the Little Ice Age and Medieval Climate Anomaly. Science, 326, 1256-1260, doi:10.1126/science.1177303.

_ J. D. Fuentes, and S. Rutherford, 2012: Underestimation of volcanic cooling in tree-ring-based reconstructions of hemispheric temperatures. Nat. Geosci., 5, 202-205.

Marchitto, T. M., R. Muscheler, J. D. Ortiz, J. D. Carriquiry, and A. van Geen, 2010: Dynamical response of the tropical Pacific Ocean to solar forcing during the early Holocene. Science, 330, 1378-1381, doi:10.1126/science.1194887.
McGregor, S., and A. Timmermann, 2011: The effect of explosive tropical volcanism on ENSO. J. Climate, 24, 2178-2191.

Meehl, G. A., W. M. Washington, T. M. L. Wigley, J. M. Arblaster, and A. Dai, 2003: Solar and greenhouse gas forcing and climate response in the twentieth century. J. Climate, 16, 426-444. and Coauthors, 2007: Global climate projections. Climate Change 2007: The Physical Science Basis. S. Solomon et al., Eds., Cambridge University Press, 747-845.

Moy, C., G. Seltzer, D. Rodbell, and D. Anderson, 2002: Variability of El Niño/Southern Oscillation activity at millennial timescales during the Holocene epoch. Nature, 420, 162165.

Muscheler, R., F. Joos, J. Beer, S. Muller, M. Vonmoos, and I. Snowball, 2006: Solar activity during the last $1000 \mathrm{yr}$ inferred from radionuclide records. Quat. Sci. Rev., 26, 82-97, doi:10.1016/j.quascirev.2006.07.012.

Newman, M., G. P. Compo, and M. A. Alexander, 2003: ENSOforced variability of the Pacific decadal oscillation. J. Climate, 16, 3853-3857.

Newton, A., R. Thunell, and L. Stott, 2006: Climate and hydrographic variability in the Indo-Pacific warm pool during the last millennium. Geophys. Res. Lett., 33, L19710, doi:10.1029/ 2006GL027234.

Nurhati, I. S., K. M. Cobb, and E. Di Lorenzo, 2011: Decadal-scale SST and salinity variations in the central tropical Pacific: Signatures of natural and anthropogenic climate change. J. Climate, 24, 3294-3308.

Peristykh, A. N., and P. E. Damon, 2003: Persistence of the Gleissberg 88-year solar cycle over the last $\sim 12,000$ years: Evidence from cosmogenic isotopes. J. Geophys. Res., 108, 1003, doi:10.1029/2002JA009390.

Quinn, T. M., T. J. Crowley, F. W. Taylor, C. Henin, P. Joannot, and Y. Join, 1998: A multicentury stable isotope record from a New Caledonia coral: Interannual and decadal sea surface temperature variability in the southwest Pacific since 1657 A.D. Paleoceanography, 13, 412-426, doi:10.1029/98PA00401.

Rayner, N. A., D. E. Parker, E. B. Horton, C. K. Folland, L. V. Alexander, D. P. Rowell, E. C. Kent, and A. Kaplan, 2003: Global analyses of sea surface temperature, sea ice, and night marine air temperature since the late nineteenth century. J. Geophys. Res., 108, 4407, doi:10.1029/2002JD002670.

_ , P. Brohan, D. Parker, C. Folland, J. Kennedy, M. Vanicek, T. Ansell, and S. Tett, 2006: Improved analyses of changes and uncertainties in sea surface temperature measured in situ since the mid-nineteenth century: The HadSST2 data set. J. Climate, 19, 446-469.

Rein, B., A. Lückge, and F. Sirocko, 2004: A major Holocene ENSO anomaly during the medieval period. Geophys. Res. Lett., 31, L17211, doi:10.1029/2004GL020161.

Rutherford, S., M. E. Mann, T. J. Osborn, R. S. Bradley, K. R. Briffa, M. K. Hughes, and P. D. Jones, 2005: Proxy-based Northern Hemisphere surface temperature reconstructions: Sensitivity to method, predictor network, target season, and target domain. J. Climate, 18, 2308-2329.

Sachs, J. P., D. Sachse, R. H. Smittenberg, Z. Zhang, D. S. Battisti, and S. Golubic, 2009: Southward movement of the Pacific intertropical convergence zone AD 1400-1850. Nat. Geosci., 2, 519-525, doi:10.1038/ngeo554.

Saint-Onge, G., J. S. Stoner, and C. Hillaire-Marcel, 2003: Holocene paleomagnetic records from the St. Lawrence Estuary, eastern Canada: Centennial- to millennial-scale geomagnetic modulation of cosmogenic isotopes. Earth Planet. Sci. Lett., 209, 113-130. 
Schneider, E. K., and Z. Zhu, 1998: Sensitivity of the simulated annual cycle of sea surface temperature in the equatorial $\mathrm{Pa}$ cific to sunlight penetration. J. Climate, 11, 1932-1950.

Schneider, N., and B. D. Cornuelle, 2005: The forcing of the Pacific decadal oscillation. J. Climate, 18, 4355-4373.

Schneider, T., 2001: Analysis of incomplete climate data: Estimation of mean values and covariance matrices and imputation of missing values. $J$. Climate, 14, 853-871.

— 2006: Analysis of incomplete data: Readings from the statistics literature. Bull. Amer. Meteor. Soc., 87, 1410-1411.

Seager, R., N. Graham, C. Herweijer, A. Gordon, Y. Kushnir, and E. Cook, 2007: Blueprints for medieval hydroclimate. Quat. Sci. Rev., 26, 2322-2336, doi:10.1016/j.quascirev.2007.04.020.

Smith, T., R. Reynolds, T. C. Peterson, and J. Lawrimore, 2008: Improvements to NOAA's historical merged land-ocean surface temperature analysis (1880-2006). J. Climate, 21, 2283-2296

Stahle, D. W., and Coauthors, 1998: Experimental dendroclimatic reconstruction of the Southern Oscillation. Bull. Amer. Meteor. Soc., 79, 2137-2152.

Steinhilber, F., J. Beer, and C. Fröhlich, 2009: Total solar irradiance during the Holocene. Geophys. Res. Lett., 36, L19704, doi:10.1029/2009GL040142.

Sterl, A., G. van Oldenborgh, W. Hazeleger, and G. Burgers, 2007: On the robustness of ENSO teleconnections. Climate Dyn., 29, 469-485, doi:10.1007/s00382-007-0251-z.

Therrell, M. D., D. W. Stahle, L. P. Ries, and H. H. Shugart, 2006: Tree-ring reconstructed rainfall variability in Zimbabwe. Climate Dyn., 26, 677-685, doi:10.1007/s00382-005-0108-2.

Thompson, D. M., T. R. Ault, M. N. Evans, J. E. Cole, and J. EmileGeay, 2011: Comparison of observed and simulated tropical climate trends using a forward model of coral of $\delta^{18} \mathrm{O}$. Geophys. Res. Lett., 38, L14706, doi:10.1029/2011GL048224.

Thomson, D. J., 1982: Spectrum estimation and harmonic analysis. Proc. IEEE, 70, 1055-1096.

Tierney, J., D. Oppo, Y. Rosenthal, J. Russell, and B. Linsley, 2010: Coordinated hydrological regimes in the Indo-Pacific region during the past two millennia. Paleoceanography, 25, PA1102, doi:10.1029/2009PA001871.

Tingley, M. P., and P. Huybers, 2010a: A Bayesian algorithm for reconstructing climate anomalies in space and time. Part I: Development and applications to paleoclimate reconstruction problems. J. Climate, 23, 2759-2781.

— climate anomalies in space and time. Part II: Comparison with the regularized expectation-maximization algorithm. J. Climate, 23, 2782-2800.

, P. F. Craigmile, M. Haran, B. Li, E. Mannshardt, and B. Rajaratnam, 2012: Piecing together the past: Statistical insights into paleoclimatic reconstructions. Quat. Sci. Rev., 35, 1-22, doi:10.1016/j.quascirev.2012.01.012.

Torrence, C., and G. P. Compo, 1998: A practical guide to wavelet analysis. Bull. Amer. Meteor. Soc., 79, 61-78.

Trenberth, K. E., 1997: The definition of El Niño. Bull. Amer. Meteor. Soc., 78, 2771-2777.

Turney, C. S. M., and J. G. Palmer, 2007: Does the El NiñoSouthern Oscillation control the interhemispheric radiocarbon offset? Quat. Res., 67, 174-180, doi:10.1016/j.yqres. 2006.08.008.

Vecchi, G. A., and A. T. Wittenberg, 2010: El Niño and our future climate: Where do we stand? WIREs Climate Change, 1, 260270.

, B. J. Soden, A. T. Wittenberg, I. M. Held, A. Leetmaa, and M. J. Harrison, 2006: Weakening of tropical Pacific atmospheric circulation due to anthropogenic forcing. Nature, 441, 73-76.

— A. Clement, and B. Soden, 2008: Examining the tropical Pacific's response to global warming. Eos, Trans. Amer. Geophys. Union, 89, 81-83.

Vimont, D. J., 2005: The contribution of the interannual ENSO cycle to the spatial pattern of decadal ENSO-like variability. J. Climate, 18, 2080-2092.

Wagner, G., and Coauthors, 2001: Presence of the solar De Vries cycle ( 205 years) during the last Ice Age. Geophys. Res. Lett., 28, 303-306.

Wahba, G., 1990: Spline Models for Observational Data. CBMSNSF Regional Conference Series in Applied Mathematics, Vol. 59, SIAM, $180 \mathrm{pp}$.

Weiss, H., and R. S. Bradley, 2001: What drives societal collapse? Science, 291, 609-610, doi:10.1126/science.1058775.

Wilson, R., E. Cook, R. D’Arrigo, N. Riedwyl, M. N. Evans, A. Tudhope, and R. Allan, 2010: Reconstructing ENSO: The influence of method, proxy data, climate forcing and teleconnections. J. Quat. Sci., 25, 62-78, doi:10.1002/jqs.1297.

Wolff, C., G. H. Haug, A. Timmermann, J. S. S. Damsté, A. Brauer, D. M. Sigman, M. A. Cane, and D. Verschuren, 2011: Reduced interannual rainfall variability in East Africa during the last ice age. Science, 333, 743-747, doi:10.1126/science.1203724.

Xie, S.-P., C. Deser, G. A. Vecchi, J. Ma, H. Teng, and A. T. Wittenberg, 2010: Global warming pattern formation: Sea surface temperature and rainfall. J. Climate, 23, 966-986.

Yamaguchi, K., and A. Noda, 2006: Global warming patterns over the North Pacific: ENSO versus AO. J. Meteor. Soc. Japan, 84, 221-241.

Yasunaka, S., and K. Hanawa, 2010: Intercomparison of historical sea surface temperature datasets. Int. J. Climatol., 31, 10561073, doi:10.1002/joc.2104.

Zebiak, S. E., and M. A. Cane, 1987: A model El Niño-Southern Oscillation. Mon. Wea. Rev., 115, 2262-2278. 